\title{
Weak convergence of explicit extragradient algorithms for solving equilibirum problems
}

\author{
Habib ur Rehman ${ }^{1}$, Poom Kumam ${ }^{1,2^{*}}$ (D) Yeol Je $\mathrm{Cho}^{3}$ and Pasakorn Yordsorn
}

\section{"Correspondence:}

poom.kum@kmutt.ac.th

${ }^{1}$ Department of Mathematics, King

Mongkut's University of Technology

Thonburi (KMUTT), Bangkok,

Thailand

${ }^{2}$ Center of Excellence in Theoretical and Computational Science

(TaCS-CoE), SCL 802 Fixed Point Laboratory, King Mongkut's University of Technology Thonburi (KMUTT), Bangkok, Thailand Full list of author information is available at the end of the article

\section{Springer}

\begin{abstract}
This paper aims to propose two new algorithms that are developed by implementing inertial and subgradient techniques to solve the problem of pseudomonotone equilibrium problems. The weak convergence of these algorithms is well established based on standard assumptions of a cost bi-function. The advantage of these algorithms was that they did not need a line search procedure or any information on Lipschitz-type bifunction constants for step-size evaluation. A practical explanation for this is that they use a sequence of step-sizes that are updated at each iteration based on some previous iterations. For numerical examples, we discuss two well-known equilibrium models that assist our well-established convergence results, and we see that the suggested algorithm has a competitive advantage over time of execution and the number of iterations.
\end{abstract}

MSC: $65 \mathrm{Y} 05 ; 65 \mathrm{~K} 15 ; 47 \mathrm{H} 05 ; 47 \mathrm{H} 10$

Keywords: Equilibrium problem; Extragradient method; Lipschitz-type conditions; Nash-Cournot equilibrium model of electricity markets

\section{Introduction}

Equilibrium problem (shortly, $E P$ ) can be considered as a general problem in the sense that it comprises many mathematical models such as variational inequality problems (shortly, $V I P)$, optimization problems, fixed point problems, complementarity problems, Nash equilibrium of noncooperative games, saddle point, vector minimization problem and the Kirszbraun problem (see e.g., [1-4]). To the best of our knowledge, the term "equilibrium problem" was initiated in 1992 by Mu and Oettli [5] and has been further strengthened by Blum and Oettli [1]. The equilibrium problem $(E P)$ is also seen as the Ky Fan inequality, since Fan [6] gives the first existence result regarding the solution of the EP. Many results about the existence of the solution of equilibrium problems have been accomplished and generalized by several authors (e.g., see [7, 8]). One of the most useful research directions in the equilibrium problem theory is to develop the iterative methods to find a numerical solution of the equilibrium problems. The research in this direction is continuing to develop new methods, leading weak convergence to strong convergence, providing modification and extension of existing algorithms which are suitable for a specific subclass of equilibrium problems. In recent years, many methods have been developed to solve equilibrium problems in finite and infinite-dimensional spaces (for instance, [9-20]).

(c) The Author(s) 2019. This article is distributed under the terms of the Creative Commons Attribution 4.0 International License (http://creativecommons.org/licenses/by/4.0/), which permits unrestricted use, distribution, and reproduction in any medium, provided you give appropriate credit to the original author(s) and the source, provide a link to the Creative Commons license, and indicate if changes were made. 
In this direction, two approaches are very well known, one of them is the proximal point method (shortly, $P P M$ ) [21] and the other one is an auxiliary problem principle [22]. The $P P M$ was introduced by Martinet [23] for monotone variational inequality problems, and later it was continued by Rockafellar [24] for monotone operators. Moudafi [21] extended the $P P M$ to EPs involving monotone bifunction. The $P P M$ method is implemented to monotone $E P$ s, i.e. the bifunction of an equilibrium problem has to be monotone. Thus, each regularized subproblem becomes strongly monotone, and a unique solution exists. This method will not guarantee the existence of the solution if the bifunction is more general monotone, like pseudomonotone. However, the auxiliary problem principle is based on the idea to develop a new problem that is identical and usually simpler to solve compared to the initial problem. This principle was early established by Cohen [25] for optimization problems and later extended for variational inequality problems [26]. Moreover, Mastroeni [22] uses the auxiliary problem principle for strongly monotone equilibrium problems.

In this paper, we focus on the second direction, including projection methods that are well known and practically easy to implement due to their easier numerical computation. As is well known, the earliest well-known projection method for VIPs is the gradient projection method. After that, many other projection methods were developed such as the extragradient method [27], the subgradient extragradient method [28], Popov's extragradient method [29], Tseng's extragradient method [30], projection and contraction schemes [31] and other hybrid and projected gradient methods [32-35]. In recent years, the equilibrium problem theory has become an attractive field for many researchers and a lot of numerical methods for solving equilibrium problems have been developed and analyzed by many authors in Hilbert spaces. Thus, Quoc [20] and Flam [36] extended the extragradient method for equilibrium problems. Recently, Hieu [37] extended the Halpern subgradient extragradient method for variational inequality problem to an equilibrium problem and also many other methods were extended and modified for variational inequality problems to equilibrium problems (see [38, 39]).

On the other hand, let us point out inertial-type algorithms, depending on the heavy ball methods of the two-order time dynamical system, Polyak [40] firstly proposed an inertial extrapolation as an acceleration process to solve the smooth convex minimization problem. The inertial method is a two-step iterative method, and the next iteration is determined by the use of two previous iterates and it can be considered as a procedure of speeding up an iterative sequence (for more details, see [40, 41]). Various inertial-like algorithms previously developed for special classes of the problem $(E P)$ can be found (for instance, in [42-44]). For the problem (EP), Moudafi [45] has done work in this direction and proposed a new inertial-type method, namely the second-order differential proximal method. This algorithm can be taken as a combination of the relaxed PPM [21] and inertial effect [40]. Recently, another type of inertial algorithm has also been introduced by Chbani and Riahi [46], by choosing a suitable inertial term and incorporating a viscositylike technique in their algorithm.

This paper proposes two modifications of Algorithm 1 (see [47]) for a class of pseudomonotone equilibrium problems motivated from some recent results (see $[28,48,49])$. These resulting algorithms combine the explicit iterative extragradient method with the subgradient method and the inertial term that is used to speed-up the iterative sequence towrads the solution. The major advantage of these methods is that they are independent 
of line search procedures and also there is no need to have a prior knowledge of Lipschitztype constants of a bifunction. Instead of that, they use a sequence of step-sizes which is updated at each iteration, based on some previous iterates. We establish the weak convergence of the resulting algorithm under standard assumptions on a cost bifunction.

We organize the rest of this paper in the following manner: In Sect. 2, we give some definitions and preliminary results that will be used throughout the paper. Section $3 \mathrm{com}$ prises our first subgradient algorithm and provides the weak convergence theorem for the proposed algorithm. Section 4 deals with proposing and analyzing the convergence of the inertial subgradient algorithm, involving a pseudomonotone bifunction. Finally, in Sect. 5, we study the numerical experiments to illustrate the computational performance of our suggested algorithms on test problems, which are modeled from a NashCournot oligopolistic equilibrium model and Nash-Cournot equilibrium models of electricity markets.

\section{Preliminaries}

Let $C$ be a closed and convex subset of a Hilbert space $\mathbb{H}$ with an inner product $\langle\cdot, \cdot\rangle$ and norm $\|\cdot\|$, respectively. Let $\mathbb{R}$ be the set of all real numbers and $\mathbb{N}$ be the set all positive integers. While $\left\{x_{n}\right\}$ is a sequence in $\mathbb{H}$, we denote the strong convergence by $x_{n} \rightarrow x$ and weak convergence by $x_{n} \rightarrow x$ as $n \rightarrow \infty$. Also, $[t]_{+}=\max \{0, t\}$ and $E P(f, C)$ denote the solution set of the equilibrium problem inside $C$ and $p$ is an element of $E P(f, C)$.

Definition 2.1 (Equilibrium problem [1]) Let $C$ be a nonempty closed convex subset of $\mathbb{H}$. Let $f$ be a bifunction from $C \times C$ to the set of real numbers $\mathbb{R}$ such that $f(x, x)=0$ for all $x \in C$. The equilibrium problem $(E P)$ for the bifunction $f$ on $C$ is to

Find $p \in C$ such that $f(p, y) \geq 0, \quad \forall y \in C$.

Definition 2.2 ([50]) Let $C$ be a closed convex subset in $\mathbb{H}$ and we denote the metric projection on $C$ by $P_{C}(x), \forall x \in \mathbb{H}$, i.e.

$$
P_{C}(x)=\arg \min \{\|y-x\|: y \in C\} .
$$

Lemma 2.1 ([51]) Let $P_{C}: \mathbb{H} \rightarrow C$ be the metric projection from $\mathbb{H}$ onto $C$. Then

(i) For all $x \in C, y \in \mathbb{H}$,

$$
\left\|x-P_{C}(y)\right\|^{2}+\left\|P_{C}(y)-y\right\|^{2} \leq\|x-y\|^{2} .
$$

(ii) $z=P_{C}(x)$ if and only if

$$
\langle x-z, y-z\rangle \leq 0
$$

Now, we define concepts of monotonicity for a bifunction (see $[1,52]$ for more details).

Definition 2.3 A bifunction $f: \mathbb{H} \times \mathbb{H} \rightarrow \mathbb{R}$ is said to be

(i) strongly monotone on $C$ if there exists a constant $\gamma>0$ such that

$$
f(x, y)+f(y, x) \leq-\gamma\|x-y\|^{2}, \quad \forall x, y \in C
$$


(ii) monotone on $C$ if

$$
f(x, y)+f(y, x) \leq 0, \quad \forall x, y \in C
$$

(iii) strongly pseudomonotone on $C$ if there exists a constant $\gamma>0$ such that

$$
f(x, y) \geq 0 \quad \Longrightarrow \quad f(y, x) \leq-\gamma\|x-y\|^{2}, \quad \forall x, y \in C
$$

(iv) pseudomonotone on $C$ if

$$
f(x, y) \geq 0 \Rightarrow f(y, x) \leq 0, \quad \forall x, y \in C ;
$$

(v) a Lipschitz-type condition on $C$ if there exist two positive constants $c_{1}, c_{2}$ such that

$$
f(x, z) \leq f(x, y)+f(y, z)+c_{1}\|x-y\|^{2}+c_{2}\|y-z\|^{2}, \quad \forall x, y, z \in C .
$$

Remark 2.1 From Definition 2.3, the following implications hold:

$$
\text { (i) } \Longrightarrow \text { (ii) } \Longrightarrow \text { (iv) and (i) } \Longrightarrow \text { (iii) } \Longrightarrow \text { (iv) }
$$

Remark 2.2 The converse of the above implications is not true in general.

Remark 2.3 If $F: C \rightarrow \mathbb{H}$ is a Lipschitz continuous operator, then the bifunction $f(x, y)=$ $\langle F(x), y-x\rangle$ satisfies Lipschitz-type condition with $c_{1}=c_{2}=\frac{L}{2}$ (see [53], Lemma 6(i)).

Further, we recall that the subdifferential of a convex function $g: C \rightarrow \mathbb{R}$ at $x \in C$ is defined by

$$
\partial g(x)=\{w \in C: g(y)-g(x) \geq\langle w, y-x\rangle, \forall y \in C\}
$$

and the normal cone of $C$ at $x \in C$ is defined by

$$
N_{C}(x)=\{w \in \mathbb{H}:\langle w, y-x\rangle \leq 0, \forall y \in C\}
$$

Lemma 2.2 ([54], p. 97) Let $C$ be a nonempty closed convex subset of a real Hilbert space $\mathbb{H}$ and $g: C \rightarrow \mathbb{R}$ be a convex, subdifferentiable, lower semicontinuous function on $C$. Then $z$ is a solution to the following convex optimization problem $\min \{g(x): x \in C\}$ if and only if $0 \in \partial g(z)+N_{C}(z)$, where $\partial g(z)$ and $N_{C}(z)$ denote the subdifferential of $g$ at $z$ and the normal cone of $C$ at $z$, respectively.

Lemma 2.3 ([55], p. 31) For all $x, y \in \mathbb{H}$ with $\mu \in \mathbb{R}$ the following relation holds:

$$
\|\mu x+(1-\mu) y\|^{2}=\mu\|x\|^{2}+(1-\mu)\|y\|^{2}-\mu(1-\mu)\|x-y\|^{2} .
$$

Lemma $2.4([56])$ Let $\phi_{n}, \delta_{n}$ and $\beta_{n}$ be sequences in $[0,+\infty)$ such that

$$
\phi_{n+1} \leq \phi_{n}+\beta_{n}\left(\phi_{n}-\phi_{n-1}\right)+\delta_{n}, \quad \forall n \geq 1, \sum_{n=1}^{+\infty} \delta_{n}<+\infty
$$


and there exists a real number $\beta$ with $0 \leq \beta_{n} \leq \beta<1$ for all $n \in \mathbb{N}$. Then the following relations hold:

(i) $\sum_{n=1}^{+\infty}\left[\phi_{n}-\phi_{n-1}\right]_{+}<\infty$, where $[t]_{+}:=\max \{t, 0\}$.

(ii) There exists $\phi^{*} \in[0,+\infty)$ such that $\lim _{n \rightarrow+\infty} \phi_{n}=\phi^{*}$.

Lemma 2.5 ([57]) Let $C$ be a nonempty set of $\mathbb{H}$ and $\left\{x_{n}\right\}$ be a sequence in $\mathbb{H}$ such that the following two conditions hold:

(i) For every $x \in C, \lim _{n \rightarrow \infty}\left\|x_{n}-x\right\|$ exists.

(ii) Every sequentially weak cluster point of $\left\{x_{n}\right\}$ is in $C$.

Then $\left\{x_{n}\right\}$ converges weakly to a point in $C$.

Assumption 2.1 We have the following assumptions on the bifunction $f: \mathbb{H} \times \mathbb{H} \rightarrow \mathbb{R}$ which are useful to prove the weak convergence of the iterative sequence $\left\{x_{n}\right\}$ generated by our proposed algorithms.

$\left(A_{1}\right) f(x, x)=0, \forall x \in C$ and $f$ is pseudomonotone on C.

$\left(A_{2}\right) f$ satisfies the Lipschitz-type conditions on $\mathbb{H}$ with two constants $c_{1}$ and $c_{2}$.

$\left(A_{3}\right) \lim _{n \rightarrow \infty} \sup f\left(x_{n}, y\right) \leq f(z, y)$ for each $y \in C$ and $\left\{x_{n}\right\} \subset C$ with $x_{n} \rightarrow z$.

$\left(A_{4}\right) f(x, \cdot)$ is convex and subdifferentiable on $C$ for every fixed $x \in C$.

\section{Subgradient explicit iterative algorithm for a class of pseudomonotone EP}

In this section, we suggest our first algorithm for finding a solution to a pseudomonotone problem $(E P)$. This algorithm comprises two convex optimization problems with a subgradient technique, used to make the computation easier, the so-called "subgradient explicit iterative algorithm" for a class of pseudomonotone $E P$. The detailed algorithm is given below.

Remark 3.1 From the definition of $\lambda_{n}$, we can see that this sequence is bounded, nonincreasing, and converges to some positive number $\lambda>0$ (for more details see [47]).

Remark 3.2 It is definite that $H_{n}$ is a half-space and $C \subset H_{n}$ (see [37]). If we restrict our constraint set to $C$ in the above convex minimization problem then we have the same algorithm (see Algorithm 1 [47]).

Lemma 3.1 From Algorithm 1, we have the following useful inequality:

$$
\lambda_{n} f\left(y_{n}, y\right)-\lambda_{n} f\left(y_{n}, x_{n+1}\right) \geq\left\langle x_{n}-x_{n+1}, y-x_{n+1}\right\rangle, \quad \forall y \in H_{n} .
$$

Proof It follows from Lemma 2.2 and the definition of $x_{n+1}$ that we have

$$
0 \in \partial_{2}\left\{\lambda_{n} f\left(y_{n}, y\right)+\frac{1}{2}\left\|x_{n}-y\right\|^{2}\right\}\left(x_{n+1}\right)+N_{H_{n}}\left(x_{n+1}\right) .
$$

Thus, for $v \in \partial f\left(y_{n}, x_{n+1}\right)$ there exists $\bar{v} \in N_{H_{n}\left(x_{n+1}\right)}$ such that

$$
\lambda_{n} v+x_{n+1}-x_{n}+\bar{v}=0,
$$

which implies that

$$
\left\langle x_{n}-x_{n+1}, y-x_{n+1}\right\rangle=\lambda_{n}\left\langle v, y-x_{n+1}\right\rangle+\left\langle\bar{v}, y-x_{n+1}\right\rangle, \quad \forall y \in H_{n} .
$$


Algorithm 1 Subgradient explicit iterative algorithm for pseudomontone $E P$

Initialization: Choose $x_{0} \in C, \lambda_{0}>0$ and $\mu \in(0,1)$.

Iterative steps: Assume $x_{n}$ and $\lambda_{n}$ are known for $n \geq 0$.

Step 1: Compute

$$
y_{n}=\arg \min \left\{\lambda_{n} f\left(x_{n}, y\right)+\frac{1}{2}\left\|x_{n}-y\right\|^{2}: y \in C\right\} .
$$

If $y_{n}=x_{n}$ then stop and $x_{n}$ is the solution of problem $(E P)$. Otherwise,

Step 2: construct a half-space first

$$
H_{n}=\left\{w \in \mathbb{H}:\left\langle x_{n}-\lambda_{n} v_{n}-y_{n}, w-y_{n}\right\rangle \leq 0\right\}
$$

where $v_{n} \in \partial f\left(x_{n}, y_{n}\right)$ and then compute

$$
x_{n+1}=\arg \min \left\{\lambda_{n} f\left(y_{n}, y\right)+\frac{1}{2}\left\|x_{n}-y\right\|^{2}: y \in H_{n}\right\} .
$$

Step 3: Compute

$$
\lambda_{n+1}=\min \left\{\lambda_{n}, \frac{\mu\left(\left\|x_{n}-y_{n}\right\|^{2}+\left\|x_{n+1}-y_{n}\right\|^{2}\right)}{2\left[f\left(x_{n}, x_{n+1}\right)-f\left(x_{n}, y_{n}\right)-f\left(y_{n}, x_{n+1}\right)\right]_{+}}\right\} .
$$

Set $n:=n+1$ and go back Step 1 .

Since $\bar{v} \in N_{H_{n}}\left(x_{n+1}\right)$ we have $\left\langle\bar{v}, y-x_{n+1}\right\rangle \leq 0$ for all $y \in H_{n}$. This implies that

$$
\left\langle x_{n}-x_{n+1}, y-x_{n+1}\right\rangle \leq \lambda_{n}\left\langle v, y-x_{n+1}\right\rangle, \quad \forall y \in H_{n} .
$$

From $v \in \partial f\left(y_{n}, x_{n+1}\right)$ and the definition of the subdifferential, we have

$$
f\left(y_{n}, y\right)-f\left(y_{n}, x_{n+1}\right) \geq\left\langle v, y-x_{n+1}\right\rangle, \quad \forall y \in \mathbb{H} .
$$

Combining (1) and (2) we obtain

$$
\lambda_{n} f\left(y_{n}, y\right)-\lambda_{n} f\left(y_{n}, x_{n+1}\right) \geq\left\langle x_{n}-x_{n+1}, y-x_{n+1}\right\rangle, \quad \forall y \in H_{n} .
$$

Lemma 3.2 Let $\left\{x_{n}\right\}$ and $\left\{y_{n}\right\}$ be generated from the Algorithm 1, then the following relation holds:

$$
\lambda_{n}\left\{f\left(x_{n}, x_{n+1}\right)-f\left(x_{n}, y_{n}\right)\right\} \geq\left\langle x_{n}-y_{n}, x_{n+1}-y_{n}\right\rangle
$$

Proof It follows from the definition of $x_{n+1}$ in Algorithm 1 and by the definition of the hyperplane $H_{n}$ that $\left\langle x_{n}-\lambda_{n} v_{n}-y_{n}, x_{n+1}-y_{n}\right\rangle \leq 0$. Thus, we get

$$
\lambda_{n}\left\langle v_{n}, x_{n+1}-y_{n}\right\rangle \geq\left\langle x_{n}-y_{n}, x_{n+1}-y_{n}\right\rangle
$$


Further, $v_{n} \in \partial f\left(x_{n}, y_{n}\right)$ and due to definition of the subdifferential, we have

$$
f\left(x_{n}, y\right)-f\left(x_{n}, y_{n}\right) \geq\left\langle v_{n}, y-y_{n}\right\rangle, \quad \forall y \in \mathbb{H}
$$

Substitute $y=x_{n+1}$ in the above expression

$$
f\left(x_{n}, x_{n+1}\right)-f\left(x_{n}, y_{n}\right) \geq\left\langle v_{n}, x_{n+1}-y_{n}\right\rangle, \quad \forall y \in \mathbb{H} .
$$

Combining (4) and (5) we obtain

$$
\lambda_{n}\left\{f\left(x_{n}, x_{n+1}\right)-f\left(x_{n}, y_{n}\right)\right\} \geq\left\langle x_{n}-y_{n}, x_{n+1}-y_{n}\right\rangle .
$$

Next, we prove an important inequality that is useful for understanding the pattern and converging analysis of the sequence generated by Algorithm 1.

Lemma 3.3 Let $f: \mathbb{H} \times \mathbb{H} \rightarrow \mathbb{R}$ be a bifunction satisfying the conditions $\left(A_{1}\right)-\left(A_{4}\right)$ (Assumption 2.1). Assume that the solution set $\operatorname{EP}(f, C)$ is nonempty. Then for all $p \in$ $E P(f, C)$ we have

$$
\left\|x_{n+1}-p\right\|^{2} \leq\left\|x_{n}-p\right\|^{2}-\left(1-\frac{\mu \lambda_{n}}{\lambda_{n+1}}\right)\left\|x_{n}-y_{n}\right\|^{2}-\left(1-\frac{\mu \lambda_{n}}{\lambda_{n+1}}\right)\left\|x_{n+1}-y_{n}\right\|^{2} \text {. }
$$

Proof By Lemma 3.1 and replacing $y=p$ we obtain

$$
\lambda_{n} f\left(y_{n}, p\right)-\lambda_{n} f\left(y_{n}, x_{n+1}\right) \geq\left\langle x_{n}-x_{n+1}, p-x_{n+1}\right\rangle .
$$

Since $f\left(p, y_{n}\right) \geq 0$ and from assumption $\left(A_{1}\right)$ we have $f\left(y_{n}, p\right) \leq 0$, which implies that

$$
\left\langle x_{n}-x_{n+1}, x_{n+1}-p\right\rangle \geq \lambda_{n} f\left(y_{n}, x_{n+1}\right) .
$$

From the definition of $\lambda_{n+1}$ we get

$$
f\left(x_{n}, x_{n+1}\right)-f\left(x_{n}, y_{n}\right)-f\left(y_{n}, x_{n+1}\right) \leq \frac{\mu\left(\left\|x_{n}-y_{n}\right\|^{2}+\left\|x_{n+1}-y_{n}\right\|^{2}\right)}{2 \lambda_{n+1}} .
$$

From Eqs. (7) and (8) we get the following:

$$
\begin{aligned}
\left\langle x_{n}-x_{n+1}, x_{n+1}-p\right\rangle \geq & \lambda_{n}\left\{f\left(x_{n}, x_{n+1}\right)-f\left(x_{n}, y_{n}\right)\right\} \\
& -\frac{\mu \lambda_{n}}{2 \lambda_{n+1}}\left\|x_{n}-y_{n}\right\|^{2}-\frac{\mu \lambda_{n}}{2 \lambda_{n+1}}\left\|x_{n+1}-y_{n}\right\|^{2} .
\end{aligned}
$$

Next, by Lemma 3.2 and Eq. (9) we obtain

$$
\begin{aligned}
\left\langle x_{n}-x_{n+1}, x_{n+1}-p\right\rangle \geq & \left\langle x_{n}-y_{n}, x_{n+1}-y_{n}\right\rangle \\
& -\frac{\mu \lambda_{n}}{2 \lambda_{n+1}}\left\|x_{n}-y_{n}\right\|^{2}-\frac{\mu \lambda_{n}}{2 \lambda_{n+1}}\left\|x_{n+1}-y_{n}\right\|^{2} .
\end{aligned}
$$


We have the following facts:

$$
\begin{aligned}
& \|a \pm b\|^{2}=\|a\|^{2}+\|b\|^{2} \pm 2\langle a, b\rangle, \\
& -2\left\langle x_{n}-x_{n+1}, x_{n+1}-p\right\rangle=-\left\|x_{n}-p\right\|^{2}+\left\|x_{n+1}-x_{n}\right\|^{2}+\left\|x_{n+1}-p\right\|^{2}, \\
& 2\left\langle y_{n}-x_{n}, y_{n}-x_{n+1}\right\rangle=\left\|x_{n}-y_{n}\right\|^{2}+\left\|x_{n+1}-y_{n}\right\|^{2}-\left\|x_{n}-x_{n+1}\right\|^{2} .
\end{aligned}
$$

Through the above expressions and Eq. (10) we have

$$
\left\|x_{n+1}-p\right\|^{2} \leq\left\|x_{n}-p\right\|^{2}-\left(1-\frac{\mu \lambda_{n}}{\lambda_{n+1}}\right)\left\|x_{n}-y_{n}\right\|^{2}-\left(1-\frac{\mu \lambda_{n}}{\lambda_{n+1}}\right)\left\|x_{n+1}-y_{n}\right\|^{2} .
$$

Let us formulate the first main convergence result of this work.

Theorem 3.1 Under the hypotheses $\left(A_{1}\right)-\left(A_{4}\right)$ (Assumption 2.1) the sequences $\left\{x_{n}\right\},\left\{y_{n}\right\}$ generated from Algorithm 1 converge weakly to an element $p$ of $E P(f, C)$. Moreover, $\lim _{n \rightarrow \infty} P_{E P(f, C)}\left(x_{n}\right)=p$.

Proof By the definition of $\lambda_{n+1}$ the sequence $\frac{\lambda_{n}}{\lambda_{n+1}} \rightarrow 1$ and $\mu \in(0,1)$, which implies that

$$
\left(1-\frac{\mu \lambda_{n}}{\lambda_{n+1}}\right) \rightarrow 1-\mu>0
$$

Next, we can easily choose $\epsilon \in(0,1-\mu)$ such that $\left(1-\frac{\mu \lambda_{n}}{\lambda_{n+1}}\right)>\epsilon, \forall n \geq n_{0}$. Due to this fact and Lemma 3.3, we obtain

$$
\left\|x_{n+1}-p\right\|^{2} \leq\left\|x_{n}-p\right\|^{2}, \quad \forall n \geq n_{0} .
$$

Furthermore, we fix an arbitrary number $m \geq n_{0}$ and consider Lemma 3.3, for all numbers $n_{0}, n_{0}+1, \ldots, m$. Summing, we obtain

$$
\begin{aligned}
\left\|x_{m+1}-p\right\|^{2} \leq & \left\|x_{n_{0}}-p\right\|^{2}-\sum_{k=n_{0}}^{m}\left(1-\frac{\mu \lambda_{k}}{\lambda_{k+1}}\right)\left\|x_{k}-y_{k}\right\|^{2} \\
& -\sum_{k=n_{0}}^{m}\left(1-\frac{\mu \lambda_{k}}{\lambda_{k+1}}\right)\left\|x_{k+1}-y_{k}\right\|^{2} \\
\leq & \left\|x_{n_{0}}-p\right\|^{2} .
\end{aligned}
$$

Taking $k \rightarrow \infty$ in Eq. (12), we can deduce the following results:

$$
\sum_{n}\left\|x_{n}-y_{n}\right\|^{2}<+\infty \quad \Longrightarrow \quad \lim _{n \rightarrow \infty}\left\|x_{n}-y_{n}\right\|=0
$$

and

$$
\sum_{n}\left\|x_{n+1}-y_{n}\right\|^{2}<+\infty \Longrightarrow \lim _{n \rightarrow \infty}\left\|x_{n+1}-y_{n}\right\|=0
$$


Further, Eqs. (11) and (12) imply that

$$
\lim _{n \rightarrow \infty}\left\|x_{n}-p\right\|=b, \quad \text { for some finite } b>0 .
$$

Moreover, from Eqs. (13), (14) and the Cauchy inequality, we get

$$
\lim _{n \rightarrow \infty}\left\|x_{k+1}-x_{k}\right\| \Longrightarrow 0
$$

Next, we show that a very sequential weak cluster point of the sequence $\left\{x_{n}\right\}$ is in $E P(f, C)$. Assume that $z$ is a weak cluster point of $\left\{x_{n}\right\}$, i.e. there exists a subsequence, denoted by $\left\{x_{n_{k}}\right\}$ of $\left\{x_{n}\right\}$, weakly converging to $z$. Then $\left\{y_{n_{k}}\right\}$ also weakly converges to $z$ and $z \in C$. Let us show that $z \in E P(f, C)$. By Lemma 3.1, the definition of $\lambda_{n+1}$ and Lemma 3.2, we have

$$
\begin{aligned}
\lambda_{n_{k}} f\left(y_{n_{k}}, y\right) \geq & \lambda_{n_{k}} f\left(y_{n_{k}}, x_{n_{k}+1}\right)+\left\langle x_{n_{k}}-x_{n_{k}+1}, y-x_{n_{k}+1}\right\rangle \\
\geq & \lambda_{n_{k}} f\left(x_{n_{k}}, x_{n_{k+1}}\right)-\lambda_{n_{k}} f\left(x_{n_{k}}, y_{n_{k}}\right)-\frac{\mu \lambda_{n_{k}}}{2 \lambda_{n_{k}+1}}\left\|x_{n_{k}}-y_{n_{k}}\right\|^{2} \\
& -\frac{\mu \lambda_{n_{k}}}{2 \lambda_{n_{k}+1}}\left\|y_{n_{k}}-x_{n_{k}+1}\right\|^{2}+\left\langle x_{n_{k}}-x_{n_{k}+1}, y-x_{n_{k}+1}\right\rangle \\
\geq & \left\langle x_{n_{k}}-y_{n_{k}}, x_{n_{k}+1}-y_{n_{k}}\right\rangle-\frac{\mu \lambda_{n_{k}}}{2 \lambda_{n_{k}+1}}\left\|x_{n_{k}}-y_{n_{k}}\right\|^{2} \\
& -\frac{\mu \lambda_{n_{k}}}{2 \lambda_{n_{k}+1}}\left\|y_{n_{k}}-x_{n_{k}+1}\right\|^{2}+\left\langle x_{n_{k}}-x_{n_{k}+1}, y-x_{n_{k}+1}\right\rangle,
\end{aligned}
$$

where $y$ is any element in $H_{n}$. It follows from (13), (14), (16) and the boundedness of $\left\{x_{n}\right\}$ that the right-hand side of the last inequality tends to zero. Using $\lambda_{n_{k}}>0$, condition $\left(A_{3}\right)$ and $y_{n_{k}} \rightarrow z$ we have

$$
0 \leq \limsup _{k \rightarrow \infty} f\left(y_{n_{k}}, y\right) \leq f(z, y), \quad \forall y \in C .
$$

Since $C \subset H_{n}$ and $z \in C$ we have $f(z, y) \geq 0, \forall y \in C$. This shows that $z \in E P(f, C)$. Thus Lemma 2.5, ensures that $\left\{x_{n}\right\}$ and $\left\{y_{n}\right\}$ converge weakly to $p$ as $n \rightarrow \infty$.

Next, we show that $\lim _{n \rightarrow \infty} P_{E P(f, C)}\left(x_{n}\right)=p$. Define $t_{n}:=P_{E P(f, C)}\left(x_{n}\right)$ for all $n \in \mathbb{N}$. Since $p \in E P(f, C)$, we have

$$
\left\|t_{n}\right\| \leq\left\|t_{n}-x_{n}\right\|+\left\|x_{n}\right\| \leq\left\|p-x_{n}\right\|+\left\|x_{n}\right\| .
$$

Thus, $\left\{t_{n}\right\}$ is bounded. In fact, by Lemma 3.3 for $n \geq n_{0}$, we deduce that

$$
\left\|x_{n+1}-t_{n+1}\right\|^{2} \leq\left\|x_{n+1}-t_{n}\right\|^{2} \leq\left\|x_{n}-t_{n}\right\|^{2}, \quad \forall n \geq n_{0} .
$$

Equations (18) and (19) imply the existence of the $\lim _{n \rightarrow \infty}\left\|x_{n}-t_{n}\right\|$. By using Lemma 3.3, for all $m>n \geq n_{0}$, we have

$$
\left\|t_{n}-x_{m}\right\|^{2} \leq\left\|t_{n}-x_{m-1}\right\|^{2} \leq \cdots \leq\left\|t_{n}-x_{n}\right\|^{2} .
$$


Next, we show that $\left\{t_{n}\right\}$ is a Cauchy sequence. Let us take $t_{m}, t_{n} \in E P(f, C)$, for $m>n \geq n_{0}$, and Lemma 2.1(i) with (20) gives

$$
\left\|t_{n}-t_{m}\right\|^{2} \leq\left\|t_{n}-x_{m}\right\|^{2}-\left\|t_{m}-x_{m}\right\|^{2} \leq\left\|t_{n}-x_{n}\right\|^{2}-\left\|t_{m}-x_{m}\right\|^{2} .
$$

The existence of $\lim _{n \rightarrow \infty}\left\|t_{n}-x_{n}\right\|$ implies that $\lim _{m, n \rightarrow \infty}\left\|t_{n}-t_{m}\right\|=0$, for all $m>n$. Consequently, $\left\{t_{n}\right\}$ is a Cauchy sequence. Since $\operatorname{EP}(f, C)$ is closed, we find that $\left\{t_{n}\right\}$ converges strongly to $p^{*} \in \operatorname{EP}(f, C)$. Now, we prove that $p^{*}=p$. It follows from Lemma 2.1(ii) and $p, p^{*} \in E P(f, C)$ that

$$
\left\langle x_{n}-t_{n}, p-t_{n}\right\rangle \leq 0
$$

Since $t_{n} \rightarrow p^{*}$ and $x_{n} \rightarrow p$, we have

$$
\left\langle p-p^{*}, p-p^{*}\right\rangle \leq 0
$$

which implies that $p=p^{*}=\lim _{n \rightarrow \infty} P_{E P(f, C)}\left(x_{n}\right)$. Further, $\left\|x_{n}-y_{n}\right\| \rightarrow 0$, implies $\lim _{n \rightarrow \infty} P_{E P(f, C)}\left(y_{n}\right)=p$.

Remark 3.3 In the case when the bifunction $f$ is strongly pseudomonotone and satisfies the Lipschitz-type condition, the linear rate of convergence can be achieved for Algorithm 1 (for more details see [47]).

\section{Modified subgradient explicit iterative algorithm for a class of pseudomonotone $E P$}

In this section, we propose an iterative scheme that involves two strong convex optimization problems with an inertial term that is used to speed up the iterative sequence, so we refer to it as a "modified explicit iterative algorithm" for a class of pseudomonotone equilibrium problems. This algorithm is a modification of Algorithm 1 that performs better than the earlier algorithm due to the inertial term. The detailed Algorithm 2 is given belowthes.

Lemma 4.1 From Algorithm 2 we have the following useful inequality:

$$
\lambda_{n} f\left(y_{n}, y\right)-\lambda_{n} f\left(y_{n}, x_{n+1}\right) \geq\left\langle w_{n}-x_{n+1}, y-x_{n+1}\right\rangle, \quad \forall y \in H_{n} .
$$

Proof The proof is very similar to Lemma 3.1.

Lemma 4.2 Let $\left\{x_{n}\right\}$ and $\left\{y_{n}\right\}$ generated from the Algorithm 2, then the following relation holds:

$$
\lambda_{n}\left\{f\left(w_{n}, x_{n+1}\right)-f\left(w_{n}, y_{n}\right)\right\} \geq\left\langle w_{n}-y_{n}, x_{n+1}-y_{n}\right\rangle
$$

Proof The proof is similar to Lemma 3.2. 
Algorithm 2 Modified subgradient explicit iterative algorithm for pseudomontone EP

Initialization: Choose $x_{-1}, x_{0} \in \mathbb{H}, \lambda_{0}>0$ and $\alpha_{n} \in[0, \sqrt{5}-2)$. Set

$w_{0}=x_{0}+\alpha_{0}\left(x_{0}-x_{-1}\right)$.

Iterative steps: Assume that $x_{n}, x_{n-1}$ and $\lambda_{n}>0$ are known for $n \geq 0$.

Step 1: Compute

$$
y_{n}=\arg \min \left\{\lambda_{n} f\left(w_{n}, y\right)+\frac{1}{2}\left\|w_{n}-y\right\|^{2}: y \in C\right\}
$$

where $w_{n}=x_{n}+\alpha_{n}\left(x_{n}-x_{n-1}\right)$. If $y_{n}=w_{n}$ then stop and $w_{n}$ is the solution of problem $(E P)$. Otherwise,

Step 2: first construct a half-space

$$
H_{n}=\left\{w \in \mathbb{H}:\left\langle w_{n}-\lambda_{n} v_{n}-y_{n}, w-y_{n}\right\rangle \leq 0\right\}
$$

where $v_{n} \in \partial f\left(w_{n}, y_{n}\right)$ and then compute

$$
x_{n+1}=\arg \min \left\{\lambda_{n} f\left(y_{n}, y\right)+\frac{1}{2}\left\|w_{n}-y\right\|^{2}: y \in H_{n}\right\} .
$$

Step 3: Assume $\mu(\alpha) \in(0,1)$ and compute

$$
\lambda_{n+1}=\min \left\{\lambda_{n}, \frac{\mu\left(\left\|w_{n}-y_{n}\right\|^{2}+\left\|x_{n+1}-y_{n}\right\|^{2}\right)}{2\left[f\left(w_{n}, x_{n+1}\right)-f\left(w_{n}, y_{n}\right)-f\left(y_{n}, x_{n+1}\right)\right]_{+}}\right\} .
$$

Set $n:=n+1$ and go back Step 1 .

Lemma 4.3 Let $f: \mathbb{H} \times \mathbb{H} \rightarrow \mathbb{R}$ be a bifunction satisfying the conditions $\left(A_{1}\right)-\left(A_{4}\right)$ as in Assumption 2.1. Assume that the solution set $E P(f, C)$ is nonempty. Then for all $p \in E P(f, C)$ we have

$$
\left\|x_{n+1}-p\right\|^{2} \leq\left\|w_{n}-p\right\|^{2}-\left(1-\frac{\mu \lambda_{n}}{\lambda_{n+1}}\right)\left\|w_{n}-y_{n}\right\|^{2}-\left(1-\frac{\mu \lambda_{n}}{\lambda_{n+1}}\right)\left\|x_{n+1}-y_{n}\right\|^{2} .
$$

Proof By Lemma 4.1 and replacing $y=p$, we obtain

$$
\lambda_{n} f\left(y_{n}, p\right)-\lambda_{n} f\left(y_{n}, x_{n+1}\right) \geq\left\langle w_{n}-x_{n+1}, p-x_{n+1}\right\rangle .
$$

Since $f\left(p, y_{n}\right) \geq 0$ and from $\left(A_{1}\right)$ we have $f\left(y_{n}, p\right) \leq 0$, which implies that

$$
\left\langle w_{n}-x_{n+1}, x_{n+1}-p\right\rangle \geq \lambda_{n} f\left(y_{n}, x_{n+1}\right) .
$$

From the definition of $\lambda_{n+1}$ we get

$$
f\left(w_{n}, x_{n+1}\right)-f\left(w_{n}, y_{n}\right)-f\left(y_{n}, x_{n+1}\right) \leq \frac{\mu\left(\left\|w_{n}-y_{n}\right\|^{2}+\left\|x_{n+1}-y_{n}\right\|^{2}\right)}{2 \lambda_{n+1}} .
$$


Combining (24) and (25) we get

$$
\begin{aligned}
\left\langle w_{n}-x_{n+1}, x_{n+1}-p\right\rangle \geq & \lambda_{n}\left\{f\left(w_{n}, x_{n+1}\right)-f\left(w_{n}, y_{n}\right)\right\} \\
& -\frac{\mu \lambda_{n}}{2 \lambda_{n+1}}\left\|w_{n}-y_{n}\right\|^{2}-\frac{\mu \lambda_{n}}{2 \lambda_{n+1}}\left\|x_{n+1}-y_{n}\right\|^{2} .
\end{aligned}
$$

Next, by Lemma 4.2 and Eq. (26) we have

$$
\begin{aligned}
\left\langle w_{n}-x_{n+1}, x_{n+1}-p\right\rangle \geq & \left\langle w_{n}-y_{n}, x_{n+1}-y_{n}\right\rangle \\
& -\frac{\mu \lambda_{n}}{2 \lambda_{n+1}}\left\|w_{n}-y_{n}\right\|^{2}-\frac{\mu \lambda_{n}}{2 \lambda_{n+1}}\left\|x_{n+1}-y_{n}\right\|^{2} .
\end{aligned}
$$

Furthermore, we have the following facts:

$$
\begin{aligned}
& 2\left\langle w_{n}-x_{n+1}, x_{n+1}-p\right\rangle=\left\|w_{n}-p\right\|^{2}-\left\|x_{n+1}-w_{n}\right\|^{2}-\left\|x_{n+1}-p\right\|^{2}, \\
& 2\left\langle w_{n}-y_{n}, x_{n+1}-y_{n}\right\rangle=\left\|w_{n}-y_{n}\right\|^{2}+\left\|x_{n+1}-y_{n}\right\|^{2}-\left\|w_{n}-x_{n+1}\right\|^{2} .
\end{aligned}
$$

Using the above facts and Eq. (27) after multiplying by 2, we get the desired result.

Now, let us formulate the second main convergence result for Algorithm 2.

Theorem 4.1 The sequences $\left\{w_{n}\right\},\left\{y_{n}\right\}$ and $\left\{x_{n}\right\}$ generated by Algorithm 2 converge weakly to the solution $p$ of the problem $(E P)$, where

$$
0<\mu<\frac{\frac{1}{2}-2 \alpha-\frac{1}{2} \alpha^{2}}{\frac{1}{2}-\alpha+\frac{1}{2} \alpha^{2}} \quad \text { and } \quad 0 \leq \alpha_{n} \leq \alpha<\sqrt{5}-2 \text {. }
$$

Proof From Lemma 4.3, we have

$$
\begin{aligned}
\left\|x_{n+1}-p\right\|^{2} & \leq\left\|w_{n}-p\right\|^{2}-\left(1-\frac{\mu \lambda_{n}}{\lambda_{n+1}}\right)\left\|w_{n}-y_{n}\right\|^{2}-\left(1-\frac{\mu \lambda_{n}}{\lambda_{n+1}}\right)\left\|x_{n+1}-y_{n}\right\|^{2} \\
& \leq\left\|w_{n}-p\right\|^{2}-\frac{1}{2}\left(1-\frac{\mu \lambda_{n}}{\lambda_{n+1}}\right)\left\|x_{n+1}-w_{n}\right\|^{2} .
\end{aligned}
$$

By the definition of $w_{n}$ in Algorithm 2, we get

$$
\begin{aligned}
\left\|w_{n}-p\right\|^{2} & =\left\|x_{n}+\alpha_{n}\left(x_{n}-x_{n-1}\right)-p\right\|^{2} \\
& =\left\|\left(1+\alpha_{n}\right)\left(x_{n}-p\right)-\alpha_{n}\left(x_{n-1}-p\right)\right\|^{2} \\
& =\left(1+\alpha_{n}\right)\left\|x_{n}-p\right\|^{2}-\alpha_{n}\left\|x_{n-1}-p\right\|^{2}+\alpha_{n}\left(1+\alpha_{n}\right)\left\|x_{n}-x_{n-1}\right\|^{2} .
\end{aligned}
$$

Further, by the definition $w_{n}$ and using the Cauchy inequality, we have

$$
\begin{aligned}
\left\|x_{n+1}-w_{n}\right\|^{2} & =\left\|x_{n+1}-x_{n}-\alpha_{n}\left(x_{n}-x_{n-1}\right)\right\|^{2} \\
& =\left\|x_{n+1}-x_{n}\right\|^{2}+\alpha_{n}^{2}\left\|x_{n}-x_{n-1}\right\|^{2}-2 \alpha_{n}\left\langle x_{n+1}-x_{n}, x_{n}-x_{n-1}\right\rangle \\
& \geq\left\|x_{n+1}-x_{n}\right\|^{2}+\alpha_{n}^{2}\left\|x_{n}-x_{n-1}\right\|^{2}-2 \alpha_{n}\left\|x_{n+1}-x_{n}\right\|\left\|x_{n}-x_{n-1}\right\|
\end{aligned}
$$




$$
\begin{aligned}
& \geq\left\|x_{n+1}-x_{n}\right\|^{2}+\alpha_{n}^{2}\left\|x_{n}-x_{n-1}\right\|^{2}-\alpha_{n}\left\|x_{n+1}-x_{n}\right\|^{2}-\alpha_{n}\left\|x_{n}-x_{n-1}\right\|^{2} \\
& \geq\left(1-\alpha_{n}\right)\left\|x_{n+1}-x_{n}\right\|^{2}+\left(\alpha_{n}^{2}-\alpha_{n}\right)\left\|x_{n}-x_{n-1}\right\|^{2} .
\end{aligned}
$$

Next, combining (28), (29) and (31), we obtain

$$
\begin{aligned}
\left\|x_{n+1}-p\right\|^{2} \leq & \left(1+\alpha_{n}\right)\left\|x_{n}-p\right\|^{2}-\alpha_{n}\left\|x_{n-1}-p\right\|^{2}+\alpha_{n}\left(1+\alpha_{n}\right)\left\|x_{n}-x_{n-1}\right\|^{2} \\
& -\varrho_{n}\left(1-\alpha_{n}\right)\left\|x_{n+1}-x_{n}\right\|^{2}-\varrho_{n}\left(\alpha_{n}^{2}-\alpha_{n}\right)\left\|x_{n}-x_{n-1}\right\|^{2} \\
= & \left(1+\alpha_{n}\right)\left\|x_{n}-p\right\|^{2}-\alpha_{n}\left\|x_{n-1}-p\right\|^{2}-\varrho_{n}\left(1-\alpha_{n}\right)\left\|x_{n+1}-x_{n}\right\|^{2} \\
& +\left[\alpha_{n}\left(1+\alpha_{n}\right)-\varrho_{n}\left(\alpha_{n}^{2}-\alpha_{n}\right)\right]\left\|x_{n}-x_{n-1}\right\|^{2} \\
= & \left(1+\alpha_{n}\right)\left\|x_{n}-p\right\|^{2}-\alpha_{n}\left\|x_{n-1}-p\right\|^{2}-Q_{n}\left\|x_{n+1}-x_{n}\right\|^{2} \\
& +R_{n}\left\|x_{n}-x_{n-1}\right\|^{2},
\end{aligned}
$$

where

$$
\begin{aligned}
& \varrho_{n}:=\frac{1}{2}\left(1-\frac{\mu \lambda_{n}}{\lambda_{n+1}}\right), \\
& Q_{n}:=\varrho_{n}\left(1-\alpha_{n}\right),
\end{aligned}
$$

and

$$
R_{n}:=\alpha_{n}\left(1+\alpha_{n}\right)-\varrho_{n}\left(\alpha_{n}^{2}-\alpha_{n}\right) .
$$

Next, we take

$$
\Lambda_{n}=\left\|x_{n}-p\right\|^{2}-\alpha_{n}\left\|x_{n-1}-p\right\|^{2}+R_{n}\left\|x_{n}-x_{n-1}\right\|^{2},
$$

and compute

$$
\begin{aligned}
\Lambda_{n+1}-\Lambda_{n}= & \left\|x_{n+1}-p\right\|^{2}-\alpha_{n+1}\left\|x_{n}-p\right\|^{2}+R_{n+1}\left\|x_{n+1}-x_{n}\right\|^{2} \\
& -\left\|x_{n}-p\right\|^{2}+\alpha_{n}\left\|x_{n-1}-p\right\|^{2}-R_{n}\left\|x_{n}-x_{n-1}\right\|^{2} \\
\leq & \left\|x_{n+1}-p\right\|^{2}-\left(1+\alpha_{n}\right)\left\|x_{n}-p\right\|^{2}+\alpha_{n}\left\|x_{n-1}-p\right\|^{2} \\
& +R_{n+1}\left\|x_{n+1}-x_{n}\right\|^{2}-R_{n}\left\|x_{n}-x_{n-1}\right\|^{2} .
\end{aligned}
$$

Using Eq. (33) in (34), we obtain

$$
\begin{aligned}
\Lambda_{n+1}-\Lambda_{n} & \leq-Q_{n}\left\|x_{n+1}-x_{n}\right\|^{2}+R_{n+1}\left\|x_{n+1}-x_{n}\right\|^{2} \\
& =-\left(Q_{n}-R_{n+1}\right)\left\|x_{n+1}-x_{n}\right\|^{2} .
\end{aligned}
$$


Furthermore, we have to compute

$$
\begin{aligned}
Q_{n}-R_{n+1} & =\varrho_{n}\left(1-\alpha_{n}\right)-\alpha_{n+1}\left(1+\alpha_{n+1}\right)+\varrho_{n+1}\left(\alpha_{n+1}^{2}-\alpha_{n+1}\right) \\
& \geq \varrho_{n}\left(1-\alpha_{n+1}\right)-\alpha_{n+1}\left(1+\alpha_{n+1}\right)+\varrho_{n}\left(\alpha_{n+1}^{2}-\alpha_{n+1}\right) \\
& =\varrho_{n}\left(1-\alpha_{n+1}\right)^{2}-\alpha_{n+1}\left(1+\alpha_{n+1}\right) \\
& \geq \varrho_{n}(1-\alpha)^{2}-\alpha(1+\alpha) \\
& =\left(\varrho_{n}-\alpha-\alpha^{2}\right)+\varrho_{n} \alpha^{2}-2 \varrho_{n} \alpha \\
& =\left(\frac{1}{2}-\alpha-\alpha^{2}+\frac{\alpha^{2}}{2}-\alpha\right)-\mu\left(\frac{\lambda_{n}}{2 \lambda_{n+1}}+\frac{\lambda_{n}}{2 \lambda_{n+1}} \alpha^{2}-\frac{\lambda_{n}}{\lambda_{n+1}} \alpha\right) \\
& =\left(\frac{1}{2}-2 \alpha-\frac{1}{2} \alpha^{2}\right)-\mu\left(\frac{\lambda_{n}}{2 \lambda_{n+1}}-\frac{\lambda_{n}}{\lambda_{n+1}} \alpha+\frac{\lambda_{n}}{2 \lambda_{n+1}} \alpha^{2}\right) .
\end{aligned}
$$

We have

$$
0<\mu<\frac{\frac{1}{2}-2 \alpha-\frac{1}{2} \alpha^{2}}{\frac{1}{2}-\alpha+\frac{1}{2} \alpha^{2}} \quad \text { and } \quad 0 \leq \alpha<\sqrt{5}-2 .
$$

This implies that, for every $0 \leq \alpha<\sqrt{5}-2$, there exist $n_{0} \geq 1$ and a fixed number

$$
\epsilon \in\left(0, \frac{1}{2}-2 \alpha-\frac{1}{2} \alpha^{2}-\mu\left(\frac{1}{2}-\alpha+\frac{1}{2} \alpha^{2}\right)\right),
$$

such that

$$
Q_{n}-R_{n+1} \geq \epsilon, \quad \forall n \geq n_{0} .
$$

Equations (35) and (37) imply that, for all $n \geq n_{0}$, we have

$$
\Lambda_{n+1}-\Lambda_{n} \leq-\left(Q_{n}-R_{n+1}\right)\left\|x_{n+1}-x_{n}\right\|^{2} \leq 0 .
$$

Hence the sequence $\left\{\Lambda_{n}\right\}$ is nonincreasing for $n \geq n_{0}$. Further, from the definition of $\Lambda_{n+1}$ we have

$$
\begin{aligned}
\Lambda_{n+1} & =\left\|x_{n+1}-p\right\|^{2}-\alpha_{n+1}\left\|x_{n}-p\right\|^{2}+R_{n+1}\left\|x_{n+1}-x_{n}\right\|^{2} \\
& \geq-\alpha_{n+1}\left\|x_{n}-p\right\|^{2} .
\end{aligned}
$$

Also, from $\Lambda_{n}$ we have

$$
\begin{aligned}
\Lambda_{n} & =\left\|x_{n}-p\right\|^{2}-\alpha_{n}\left\|x_{n-1}-p\right\|^{2}+R_{n}\left\|x_{n}-x_{n-1}\right\|^{2} \\
& \geq\left\|x_{n}-p\right\|^{2}-\alpha_{n}\left\|x_{n-1}-p\right\|^{2} .
\end{aligned}
$$


Equation (40) implies that, for $n \geq n_{0}$, we have

$$
\begin{aligned}
\left\|x_{n}-p\right\|^{2} & \leq \Lambda_{n}+\alpha_{n}\left\|x_{n-1}-p\right\|^{2} \\
& \leq \Lambda_{n_{0}}+\alpha\left\|x_{n-1}-p\right\|^{2} \\
& \leq \cdots \leq \Lambda_{n_{0}}\left(\alpha^{n-n_{0}}+\cdots+1\right)+\alpha^{n-n_{0}}\left\|x_{n_{0}}-p\right\|^{2} \\
& \leq \frac{\Lambda_{n_{0}}}{1-\alpha}+\alpha^{n-n_{0}}\left\|x_{n_{0}}-p\right\|^{2} .
\end{aligned}
$$

Combining (39) and (41) we obtain

$$
\begin{aligned}
-\Lambda_{n+1} & \leq \alpha_{n+1}\left\|x_{n}-p\right\|^{2} \\
& \leq \alpha\left\|x_{n}-p\right\|^{2} \\
& \leq \alpha \frac{\Lambda_{n_{0}}}{1-\alpha}+\alpha^{n-n_{0}+1}\left\|x_{n_{0}}-p\right\|^{2} .
\end{aligned}
$$

It follows from (38) and (42) that

$$
\begin{aligned}
\epsilon \sum_{n=n_{0}}^{k}\left\|x_{n+1}-x_{n}\right\|^{2} & \leq \Lambda_{n_{0}}-\Delta_{k+1} \\
& \leq \Lambda_{n_{0}}+\alpha \frac{\Delta_{n_{0}}}{1-\alpha}+\alpha^{k-n_{0}+1}\left\|x_{n_{0}}-p\right\|^{2} \\
& \leq \frac{\Lambda_{n_{0}}}{1-\alpha}+\left\|x_{n_{0}}-p\right\|^{2} .
\end{aligned}
$$

Letting $k \rightarrow \infty$ in (43) we have $\sum_{n=1}^{\infty}\left\|x_{n+1}-x_{n}\right\|^{2}<+\infty$. This implies that

$$
\left\|x_{n+1}-x_{n}\right\| \rightarrow 0 \quad \text { as } n \rightarrow \infty
$$

From Eqs. (30) and (44) we have

$$
\left\|x_{n+1}-w_{n}\right\| \rightarrow 0 \quad \text { as } n \rightarrow \infty .
$$

Moreover, by Lemma 2.4, Eq. (32) and $\sum_{n=1}^{\infty}\left\|x_{n+1}-x_{n}\right\|^{2}<+\infty$,

$$
\lim _{n \rightarrow \infty}\left\|x_{n}-p\right\|^{2}=b
$$

Thus, from Eqs. (29), (44) and (46),

$$
\lim _{n \rightarrow \infty}\left\|w_{n}-p\right\|^{2}=b
$$

also

$$
0 \leq\left\|x_{n}-w_{n}\right\|=\left\|x_{n}-x_{n+1}\right\|+\left\|x_{n+1}-w_{n}\right\| \rightarrow 0 \quad \text { as } n \rightarrow \infty .
$$


To show $\lim _{n \rightarrow \infty}\left\|y_{n}-p\right\|^{2}=b$, we use Lemma 4.3 for $n \geq n_{0}$, which gives

$$
\begin{aligned}
(1 & \left.-\frac{\mu \lambda_{n}}{\lambda_{n+1}}\right)\left\|w_{n}-y_{n}\right\|^{2} \\
& \leq\left\|w_{n}-p\right\|^{2}-\left\|x_{n+1}-p\right\|^{2} \\
& \leq\left(\left\|w_{n}-p\right\|+\left\|x_{n+1}-p\right\|\right)\left(\left\|w_{n}-p\right\|-\left\|x_{n+1}-p\right\|\right) \\
& \leq\left(\left\|w_{n}-p\right\|+\left\|x_{n+1}-p\right\|\right)\left\|x_{n+1}-w_{n}\right\| \rightarrow 0 \quad \text { as } n \rightarrow \infty
\end{aligned}
$$

and

$$
0 \leq\left\|x_{n}-y_{n}\right\|=\left\|x_{n}-w_{n}\right\|+\left\|w_{n}-y_{n}\right\| \rightarrow 0 \quad \text { as } n \rightarrow \infty .
$$

Further, (44), (46) and (50) imply that

$$
\left\|x_{n+1}-y_{n}\right\| \rightarrow 0 \text { as } n \rightarrow \infty, \quad \text { and } \quad \lim _{n \rightarrow \infty}\left\|y_{n}-p\right\|^{2}=b .
$$

This implies that the sequences $\left\{x_{n}\right\},\left\{w_{n}\right\}$ and $\left\{y_{n}\right\}$ are bounded, and for every $p \in E P(f, C)$, the $\lim _{n \rightarrow \infty}\left\|x_{n}-p\right\|^{2}$ exists. Now, further we show that for very sequential weak cluster point of the sequence $\left\{x_{n}\right\}$ is in $E P(f, C)$. Assume that $z$ is a weak cluster point of $\left\{x_{n}\right\}$, i.e., there exists a subsequence, denoted by $\left\{x_{n_{k}}\right\}$, of $\left\{x_{n}\right\}$ weakly converging to $z$. Then $\left\{y_{n_{k}}\right\}$ also weakly converges to $z$ and $z \in C$. Let us show that $z \in E P(f, C)$. By Lemma 4.1, the definition of $\lambda_{n+1}$ and Lemma 4.2, we have

$$
\begin{aligned}
\lambda_{n_{k}} f\left(y_{n_{k}}, y\right) \geq & \lambda_{n_{k}} f\left(y_{n_{k}}, x_{n_{k}+1}\right)+\left\langle w_{n_{k}}-x_{n_{k}+1}, y-x_{n_{k}+1}\right\rangle \\
\geq & \lambda_{n_{k}} f\left(w_{n_{k}}, x_{n_{k+1}}\right)-\lambda_{n_{k}} f\left(w_{n_{k}}, y_{n_{k}}\right)-\frac{\mu \lambda_{n_{k}}}{2 \lambda_{n_{k}+1}}\left\|w_{n_{k}}-y_{n_{k}}\right\|^{2} \\
& -\frac{\mu \lambda_{n_{k}}}{2 \lambda_{n_{k}+1}}\left\|y_{n_{k}}-x_{n_{k}+1}\right\|^{2}+\left\langle w_{n_{k}}-x_{n_{k}+1}, y-x_{n_{k}+1}\right\rangle \\
\geq & \left\langle w_{n_{k}}-y_{n_{k}}, x_{n_{k}+1}-y_{n_{k}}\right\rangle-\frac{\mu \lambda_{n_{k}}}{2 \lambda_{n_{k}+1}}\left\|w_{n_{k}}-y_{n_{k}}\right\|^{2} \\
& -\frac{\mu \lambda_{n_{k}}}{2 \lambda_{n_{k}+1}}\left\|y_{n_{k}}-x_{n_{k}+1}\right\|^{2}+\left\langle w_{n_{k}}-x_{n_{k}+1}, y-x_{n_{k}+1}\right\rangle,
\end{aligned}
$$

where $y$ is any element in $H_{n}$. It follows from (45), (49), (51) and the boundedness of $\left\{x_{n}\right\}$ that the right-hand side of the last inequality tends to zero. Using $\lambda_{n_{k}}>0$, condition $\left(A_{3}\right)$ and $y_{n_{k}} \rightarrow z$, we have

$$
0 \leq \limsup _{k \rightarrow \infty} f\left(y_{n_{k}}, y\right) \leq f(z, y), \quad \forall y \in \mathbb{H}_{n} .
$$

Since $C \subset H_{n}$ and $z \in C$, we have $f(z, y) \geq 0, \forall y \in C$. This shows that $z \in E P(f, C)$. Thus Lemma 2.5, ensures that $\left\{w_{n}\right\},\left\{x_{n}\right\}$ and $\left\{y_{n}\right\}$ converge weakly to $p$ as $n \rightarrow \infty$.

Remark 4.1 The knowledge of the Lipschitz-type constants is not mandatory to build up the sequence $\left\{x_{n}\right\}$ in Algorithm 2 and to get the convergence result in Theorem 4.1. 


\section{Computational experiment}

In this section, some numerical results will be presented in order to test Algorithms 1 and 2 with the recent Heiu algorithm in [47]. The MATLAB codes run on a PC (with Intel(R) Core(TM)i3-4010U CPU @ 1.70 GHz 1.70 GHz, RAM 4.00 GB) under MATLAB version 9.5 (R2018b).

\subsection{Nash-Cournot oligopolistic equilibrium model}

We consider an extension of a Nash-Cournot oligopolistic equilibrium model [2]. Assume that there are $m$ companies that are producing the same commodity. Let $x$ denote the vector whose entry $x_{j}$ stands for the quantity of the commodity produced by company $j$. We suppose that the price $p_{j}(s)$ is a decreasing affine function of $s$ with $s=\sum_{j=1}^{m} x_{j}$ i.e. $p_{j}(s)=\alpha_{j}-\beta_{j} s$, where $\alpha_{j}>0, \beta_{j}>0$. Then the profit made by company $j$ is given by $f_{j}(x)=$ $p_{j}(s) x_{j}-c_{j}\left(x_{j}\right)$, where $c_{j}\left(x_{j}\right)$ is the tax and fee for generating $x_{j}$. Suppose that $C_{j}=\left[x_{j}^{\min }, x_{j}^{\max }\right]$ is the strategy set of company $j$. Then the strategy set of the model is $C:=C_{1} \times C_{2} \times \cdots \times$ $C_{m}$. Actually, each company wants to maximize its profit by choosing the corresponding production level under the presumption that the production of the other companies is a parameter input. A frequently used approach to dealing with this model is based upon the well-known Nash equilibrium concept. We recall that a point $x^{*} \in C=C_{1} \times C_{2} \times \cdots \times C_{m}$ is an equilibrium point of the model if

$$
f_{j}\left(x^{*}\right) \geq f_{j}\left(x^{*}\left[x_{j}\right]\right), \quad \forall x_{j} \in C_{j}, \forall j=1,2, \ldots, m .
$$

where the vector $x^{*}\left[x_{j}\right]$ stands for the vector attain from $x^{*}$ by replacing $x_{j}^{*}$ with $x_{j}$. By taking $f(x, y):=\psi(x, y)-\psi(x, x)$ with $\psi(x, y):=-\sum_{j=1}^{m} f_{j}\left(x\left[y_{j}\right]\right)$, the problem of finding a Nash equilibrium point of the model can be formulated as

$$
\text { Find } x^{*} \in C: f\left(x^{*}, y\right) \geq 0, \quad \forall y \in C \text {. }
$$

Now, assume that the tax-fee function $c_{j}\left(x_{j}\right)$ is increasing and affine for every $j$. This assumption means that both of the tax and fee for producing a unit are increasing as the quantity of the production gets larger. As in $[20,53]$, the bifunction $f$ can be formulated in the form of $f(x, y)=\langle P x+Q y+q, y-x\rangle$, where $q \in \mathbb{R}^{m}$ and $P, Q$ are two matrices of order $m$ such that $Q$ is symmetric positive semidefinite and $Q-P$ is symmetric negative semidefinite.

For Experiment 5.1 we take $x_{-1}=(10,0,10,1,10)^{T}, x_{0}=(1,3,1,1,2)^{T}, C=\{x:-2 \leq$ $\left.x_{i} \leq 5\right\}$ and $y$-axes represent for the value of $D_{n}=\left\|w_{n}-y_{n}\right\|$ while the $\mathrm{x}$-axes represent for the number of iterations or elapsed time (in seconds).

\subsubsection{Algorithm 2 nature in terms of different values of $\alpha_{n}$}

Figures 1 and 2 illustrate the numerical results for the first 120 iterations of Algorithm 2 (shortly, MSgEIA) with respect to using different values of $\alpha_{n}$. For these results, we use parameters $\alpha_{n}=0.22,0.16,0.11,0.07,0.03, \lambda_{0}=1$ and $\mu=0.11$. These two figures are useful for choosing the best possible value of $\alpha_{n}$.

\subsubsection{Algorithm 2 comparison with existing algorithms}

Figures 3 and 4 describe the numerical results for the first 100 iterations of Algorithm 2 [Modified subgradient explicit iterative algorithm (shortly, MSgEIA)] compared with Al- 


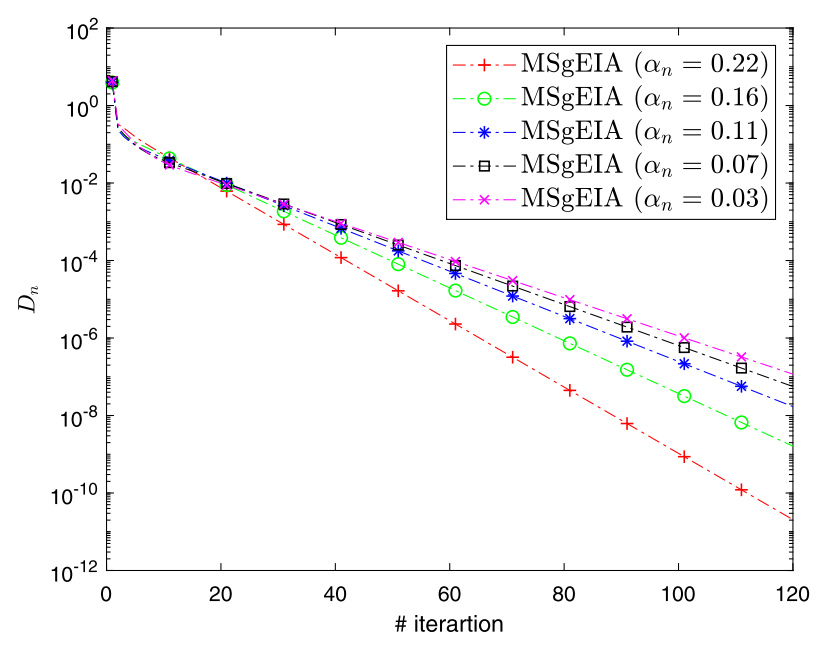

Figure 1 Experiment 5.1: Algorithm 2 behavior in terms of iterations relative to different values of $\alpha_{n}$

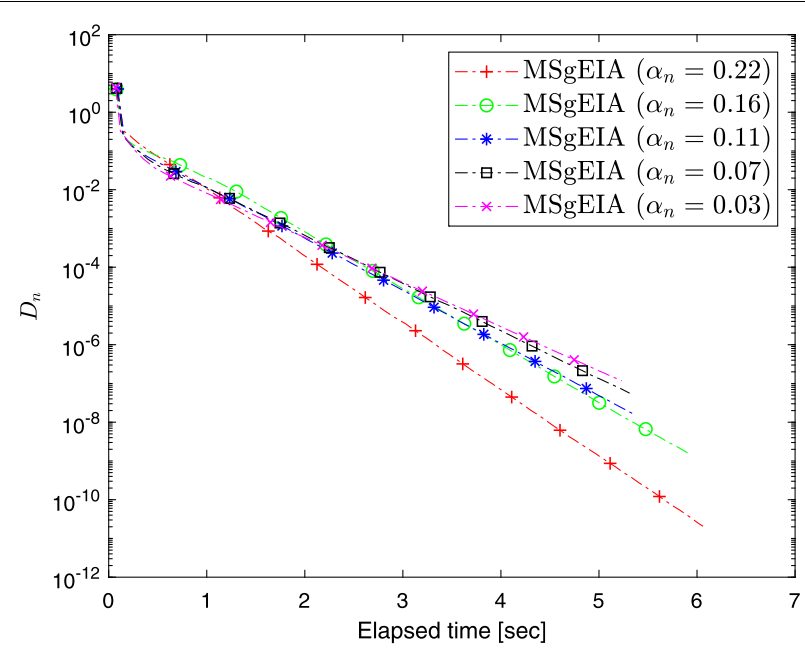

Figure 2 Experiment 5.1: Algorithm 2 behavior in terms of elapsed time relative to different values of $\alpha_{n}$

gorithm 1 [Subgradient explicit iterative algorithm (shortly, SgEIA)] and explicit Algorithm 1 [Explicit iterative algorithm (shortly, EIA) [47]] in terms of no. of iterations and elapsed time in seconds.

(i) For Explicit iterative algorithm (EIA) we use the parameters $\mu=0.11, \lambda_{0}=1$ and $D_{n}=\left\|x_{n}-y_{n}\right\|$.

(ii) For Subgradient explicit iterative algorithm (SgEIA) we use the parameters $\mu=0.11, \lambda_{0}=1$ and $D_{n}=\left\|x_{n}-y_{n}\right\|$.

(iii) For Modified subgradient explicit iterative algorithm (MSgEIA) we use the parameters $\alpha_{n}=0.12, \mu=0.11, \lambda_{0}=1$ and $D_{n}=\left\|w_{n}-y_{n}\right\|$.

\subsection{Nash-Cournot equilibrium models of electricity markets}

In this experiment, we apply our proposed algorithm to a Nash-Cournot equilibrium model of electricity markets as in [13]. In this model, it is considered that there are three 


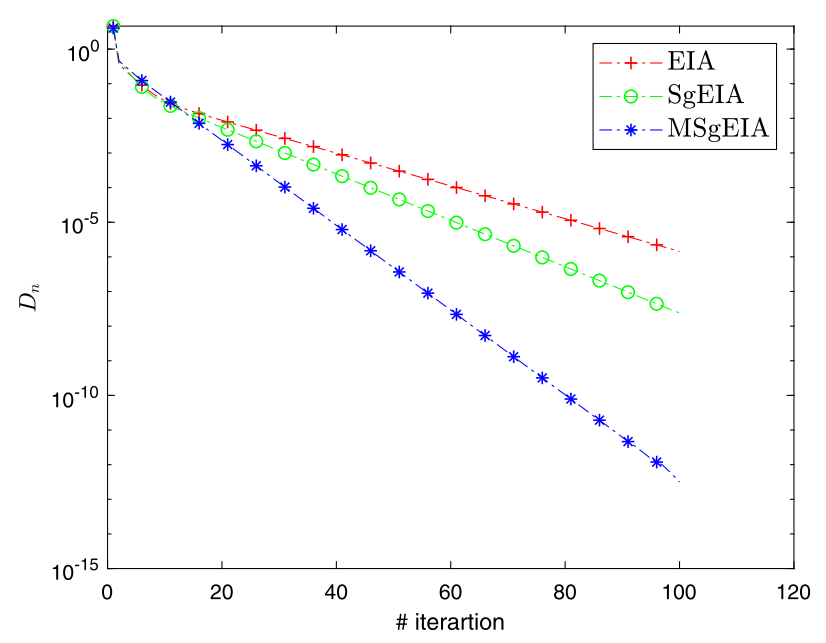

Figure 3 Experiment 5.1: Algorithm 2 comparison in terms of iterations

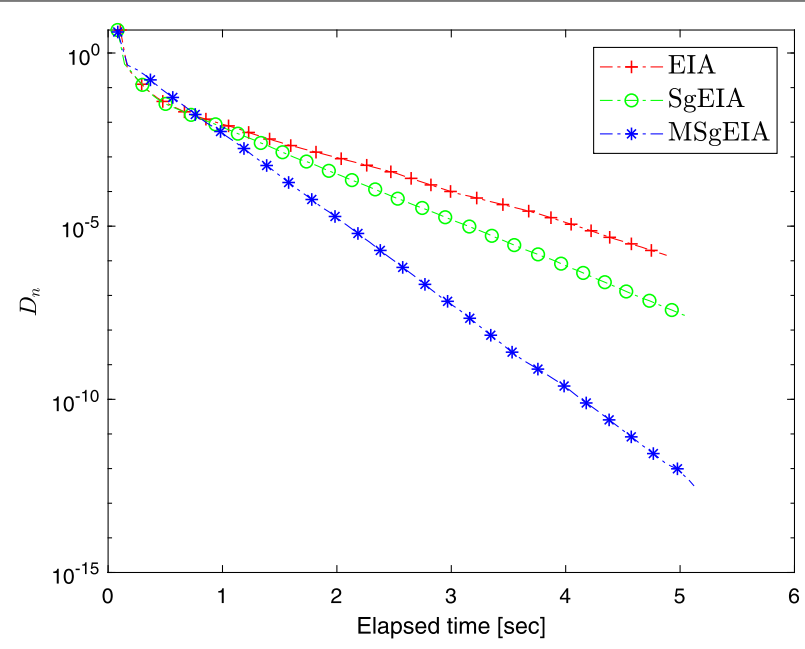

Figure 4 Experiment 5.1: Algorithm 2 comparison in terms of elapsed time

electricity companies $i(i=1,2,3)$. Each company $i$ has its own, several generating units with index set $I_{i}$. In this experiment, suppose that $I_{1}=\{1\}, I_{2}=\{2,3\}$ and $I_{3}=\{4,5,6\}$. Let $x_{j}$ be the power generation of units $j(j=1, \ldots, 6)$ and suppose that the electricity price $p$ can be expressed as by $p=378.4-2 \sum_{j=1}^{6} x_{j}$. The cost of a generating unit $j$ is illustrated by

$$
c_{j}\left(x_{j}\right):=\max \left\{\stackrel{\circ}{c}_{j}\left(x_{j}\right), \dot{c}_{j}\left(x_{j}\right)\right\}
$$

with

$$
{\stackrel{\circ}{c_{j}}}_{j}\left(x_{j}\right):=\frac{\stackrel{\circ}{\alpha}_{j}}{2} x_{j}^{2}+\stackrel{\circ}{\beta}_{j} x_{j}+\stackrel{\circ}{\gamma}_{j}
$$


Table 1 The parameter values used in this experiment

\begin{tabular}{lllllll}
\hline$j$ & $\stackrel{\circ}{\alpha}_{j}$ & $\stackrel{\circ}{\beta}_{j}$ & $\stackrel{\circ}{\gamma}_{j}$ & $\dot{\alpha}_{j}$ & $\dot{\beta}_{j}$ & $\dot{\gamma}_{j}$ \\
\hline 1 & 0.0400 & 2.00 & 0.00 & 2.0000 & 1.0000 & 25.0000 \\
2 & 0.0350 & 1.75 & 0.00 & 1.7500 & 1.0000 & 28.5714 \\
3 & 0.1250 & 1.00 & 0.00 & 1.0000 & 1.0000 & 8.0000 \\
4 & 0.0116 & 3.25 & 0.00 & 3.2500 & 1.0000 & 86.2069 \\
5 & 0.0500 & 3.00 & 0.00 & 3.0000 & 1.0000 & 20.0000 \\
6 & 0.0500 & 3.00 & 0.00 & 3.0000 & 1.0000 & 20.0000 \\
\hline
\end{tabular}

Table 2 The parameter values used in this experiment

\begin{tabular}{lrrrrrr}
\hline & $j$ & & & & & \\
\cline { 2 - 7 } & 1 & \multicolumn{1}{c}{2} & \multicolumn{1}{c}{3} & \multicolumn{1}{c}{4} & \multicolumn{1}{c}{5} & \multicolumn{1}{c}{0} \\
\hline$x_{j}^{\min }$ & 0 & 0 & 0 & 0 & 0 & 0 \\
$x_{j}^{\max }$ & 80 & 80 & 50 & 55 & 30 & 40 \\
\hline
\end{tabular}

and

$$
\dot{c}_{j}\left(x_{j}\right):=\dot{\alpha}_{j} x_{j}+\frac{\dot{\beta}_{j}}{\dot{\beta}_{j}+1} \dot{\gamma}_{j} \dot{-1}_{\dot{\beta}_{j}}\left(x_{j}\right)^{\frac{\left(\dot{\beta}_{j+1}\right)}{\dot{\beta}_{j}}}
$$

where the parameter values are given in $\stackrel{\circ}{\alpha}_{j}, \stackrel{\circ}{\beta}_{j}, \stackrel{\circ}{\gamma}_{j}, \dot{\leftrightarrow}_{j}, \dot{\beta}_{j}$ and $\dot{\gamma}_{j}$ are given in Table 1. Suppose the profit of company $i$ is given by

$$
f_{i}(x):=p \sum_{j \in I_{i}} x_{j}-\sum_{j \in I_{i}} c_{j}\left(x_{j}\right)=\left(378.4-2 \sum_{l=1}^{6} x_{l}\right) \sum_{j \in I_{i}} x_{j}-\sum_{j \in I_{i}} c_{j}\left(x_{j}\right)
$$

where $x=\left(x_{1}, \ldots, x_{6}\right)^{T}$ subject to the constraint $x \in C:=\left\{x \in \mathbb{R}^{6}: x_{j}^{\min } \leq x_{j} \leq x_{j}^{\max }\right\}$, with $x_{j}^{\min }$ and $x_{j}^{\max }$ given in Table 2 .

Next, we define the equilibrium function $f$ by

$$
f(x, y):=\sum_{i=1}^{3}\left(\phi_{i}(x, x)-\phi_{i}(x, y)\right)
$$

where

$$
\phi_{i}(x, y):=\left[378.4-2\left(\sum_{j \notin I_{i}} x_{j}+\sum_{j \in I_{i}} y_{j}\right)\right] \sum_{j \in I_{i}} y_{j}-\sum_{j \in I_{i}} c_{j}\left(y_{j}\right) .
$$

The Nash-Cournot equilibrium models of electricity markets can be reformulated as an equilibrium problem (see [58]):

Find $x^{*} \in C \quad$ such that $f\left(x^{*}, y\right) \geq 0, \quad \forall y \in C$.

For Experiment 5.2, we take $x_{-1}=(10,0,10,1,10,1)^{T}, x_{0}=(48,48,30,27,18,24)^{T}$, and the y-axes represent for the value of $D_{n}$ while the x-axes represent the number of iterations or elapsed time (in seconds). 


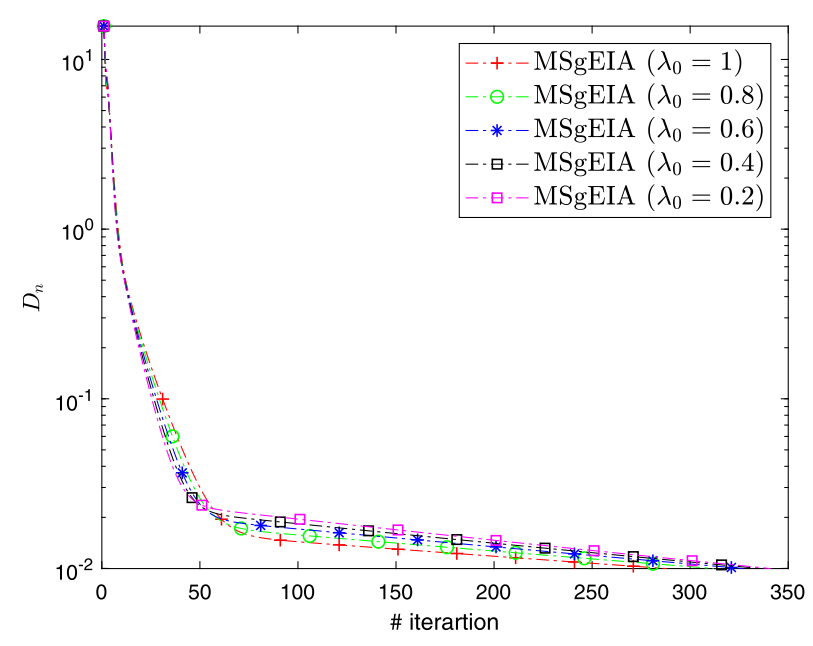

Figure 5 Experiment 5.2: Algorithm 2 behavior in terms of iterations relative to different values of $\lambda_{0}$

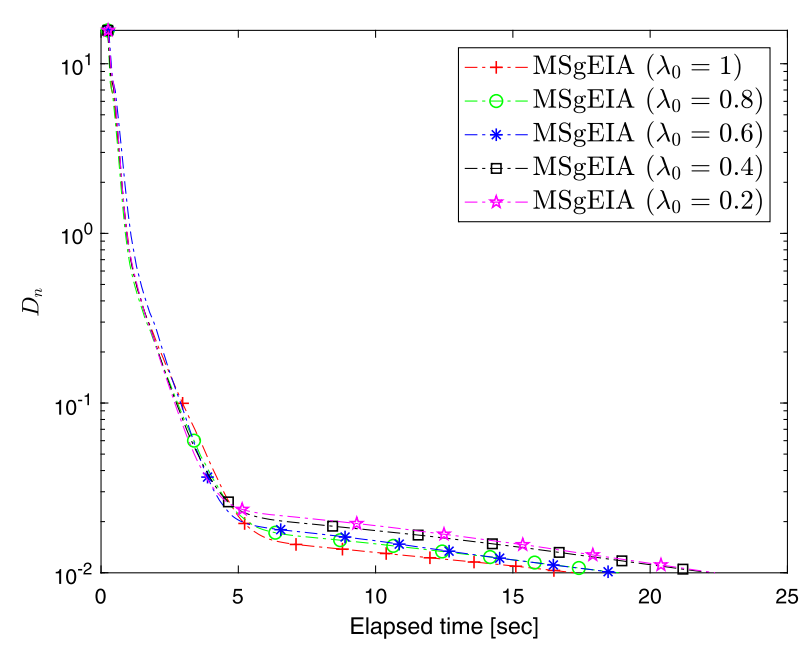

Figure 6 Experiment 5.2: Algorithm 2 behavior in terms of elapsed time relative to different values of $\lambda_{0}$

\subsubsection{Algorithm 2 nature in terms of different values of $\lambda_{0}$}

Figures 5 and 6 describe the numerical results of Algorithm 2 (MSgEIA) with respect to using different values of $\lambda_{0}$, in terms of no. of iterations and elapsed time in seconds relative to $D_{n}=\left\|x_{n+1}-x_{n}\right\|$. For these results, we use the parameters $\alpha_{n}=0.20$ $\lambda_{0}=1,0.8,0.6,0.4,0.2, \mu=0.24$ and $\epsilon=10^{-2}$.

\subsubsection{Algorithm 2 comparison with existing algorithms}

Figures 7 and 8 describe the numerical results of Algorithm 2 [Modified subgradient explicit iterative algorithm (MSgEIA)] compared with Algorithm 1 [Subgradient explicit iterative algorithm (SgEIA)] and Algorithm 1 [Explicit iterative algorithm (EIA) [47]] in terms of no. of iterations and elapsed time in seconds.

(i) For the Explicit iterative algorithm (EIA) we use the parameters $\mu=0.2, \lambda_{0}=0.6$ and $D_{n}=\left\|x_{n+1}-x_{n}\right\|$. 


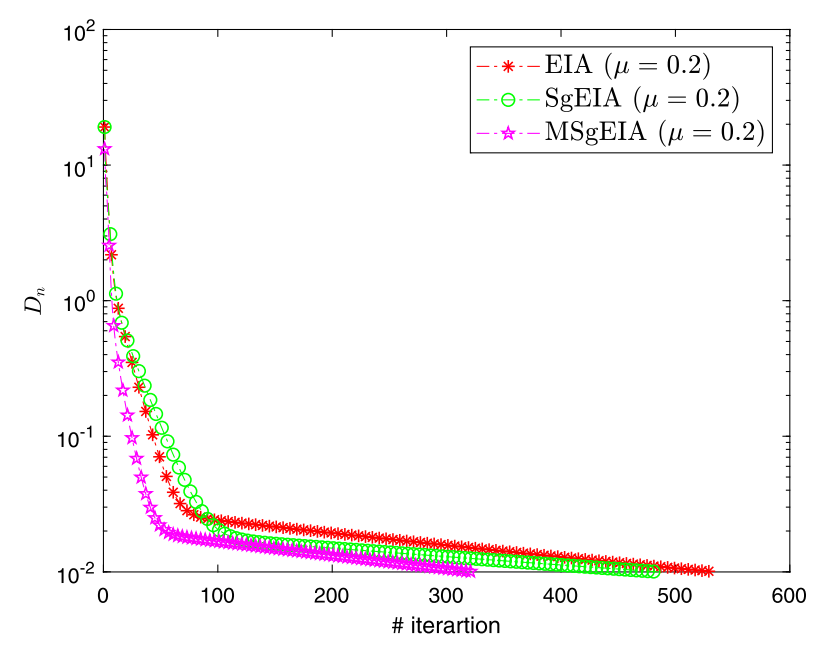

Figure 7 Experiment 5.2: Algorithm 2 compared in terms of iterations

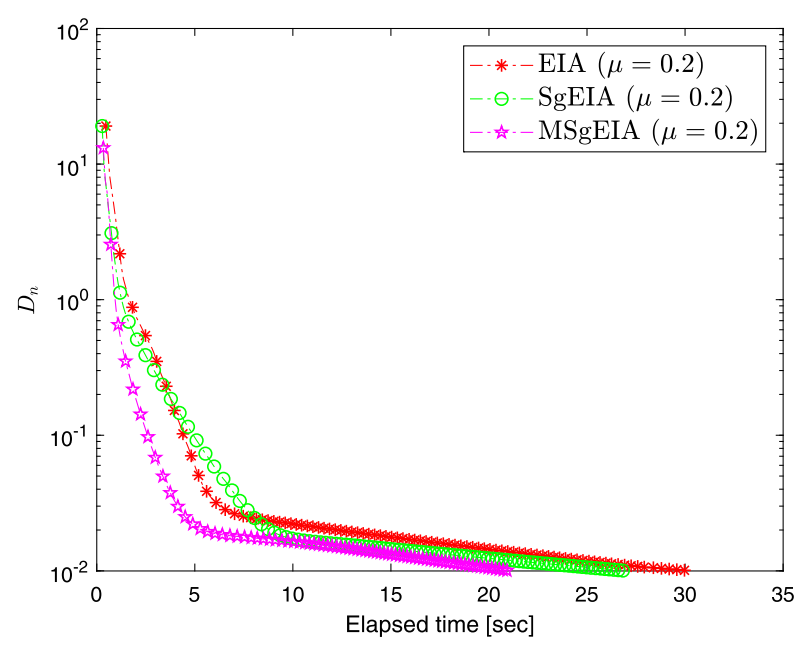

Figure 8 Experiment 5.2: Algorithm 2 compared in terms of elapsed time

(ii) For Subgradient explicit iterative algorithm (SgEIA) we use the parameters $\mu=0.2$, $\lambda_{0}=0.6$ and $D_{n}=\left\|x_{n+1}-x_{n}\right\|$.

(iii) For Modified subgradient explicit iterative algorithm (MSgEIA) we use the parameters $\alpha_{n}=0.20, \mu=0.2, \lambda_{0}=0.6$ and $D_{n}=\left\|x_{n+1}-x_{n}\right\|$.

\subsection{Two-dimensional (2-D) pseudomonotone EP}

Let us consider the following bifunction:

$$
f(x, y)=\langle F(x), y-x\rangle,
$$

where

$$
F(x)=\left(\begin{array}{c}
\left(x_{1}^{2}+\left(x_{2}-1\right)^{2}\right)\left(1+x_{2}\right) \\
-x_{1}^{3}-x_{1}\left(x_{2}-1\right)^{2}
\end{array}\right) \quad \text { with } C=\left\{x \in \mathbb{R}^{2}:-10 \leq x_{i} \leq 10\right\} .
$$



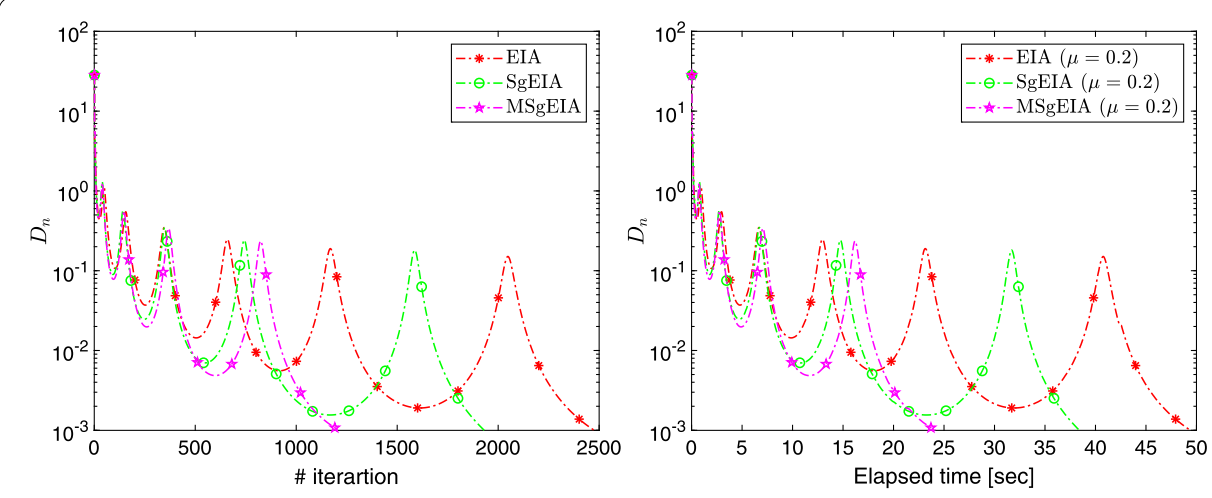

Figure 9 Algorithm 2 compared in terms of no. of iterations and elapsed time

The bifunction is not monotone on $C$ but pseudomonotone (for more details see p. 10, $[59,60])$. Figure 9 illustrates the numerical results of comparison of Algorithm 2 with two other algorithms, with $x_{-1}=(5,5)^{T}$ and $x_{0}=(10,10)^{T}$.

\section{Conclusion}

In this paper, we propose two algorithms by incorporating the subgradient and inertial technique with an explicit iterative algorithm, which can solve the problem of a pseudomonotone equilibrium. The evaluation of the step-size did not require a line search procedure or information on the Lipchitz-type constants of the bifunction. Rather, one uses a step-size sequence that can be updated on each iteration with the help of previous iterations. We have presented various numerical results to show the computational performance of our algorithm in comparison with other algorithms. These numerical results have also explained that the algorithm with inertial effects seems to perform better than without inertial effects.

\section{Acknowledgements}

The authors would like to say thanks to Professor Gabor Kassay and Auwal Bala Abubakar to providing a suggestion regarding about the Matlab program.

\section{Funding}

This project was supported by Theoretical and Computational Science (TaCS) Center under Computational and Applied Science for Smart research Innovation Cluster (CLASSIC), Faculty of Science, KMUTT. Habib ur Rehman was supported by the Petchra Pra Jom Klao Doctoral Scholarship Academic for Ph.D. Program at KMUTT (Grant No. 39/2560).

Availability of data and materials

Not applicable.

\section{Competing interests}

The authors declare that they have no competing interests.

Authors' contributions

All authors contributed equally and significantly in writing this article. All authors read and approved the final manuscript.

\section{Author details}

${ }^{1}$ Department of Mathematics, King Mongkut's University of Technology Thonburi (KMUTT), Bangkok, Thailand. ${ }^{2}$ Center of Excellence in Theoretical and Computational Science (TaCS-CoE), SCL 802 Fixed Point Laboratory, King Mongkut's University of Technology Thonburi (KMUTT), Bangkok, Thailand. ${ }^{3}$ Department of Mathematics Education, Gyeongsang National University, Jinju, South Korea.

\section{Publisher's Note}

Springer Nature remains neutral with regard to jurisdictional claims in published maps and institutional affiliations. 
Received: 17 June 2019 Accepted: 25 October 2019 Published online: 07 November 2019

\section{References}

1. Blum, E.: From optimization and variational inequalities to equilibrium problems. Math. Stud. 63, 123-145 (1994)

2. Facchinei, F., Pang, J.-S.: Finite Dimensional Variational Inequalities and Complementarity Problems. Springer, New York (2003)

3. Konnov, I.V.: Equilibrium Models and Variational Inequalities. Elsevier, Amsterdam (2007)

4. Giannessi, F., Maugeri, A.: Variational Inequalities and Network Equilibrium Problems. Springer, New York (1995)

5. Muu, L., Oettli, W.: Convergence of an adaptive penalty scheme for finding constrained equilibria. Nonlinear Anal., Theory Methods Appl. 18(12), 1159-1166 (1992). https://doi.org/10.1016/0362-546x(92)90159-c

6. Fan, K.: A minimax inequality and applications. In: Shisha, O. (ed.) Inequalities III. Academic Press, New York (1972)

7. Yuan, G.X.-Z.: KKM Theory and Applications in Nonlinear Analysis. CRC Press, New York (1999)

8. Brézis, H., Nirenberg, L., Stampacchia, G.: A remark on Ky Fan's minimax principle. Boll. Unione Mat. Ital. 1(2), 257-264 (2008)

9. Anh, P.N., Le Thi, H.A.: An Armijo-type method for pseudomonotone equilibrium problems and its applications. J. Glob. Optim. 57(3), 803-820 (2012). https://doi.org/10.1007/s10898-012-9970-8

10. Anh, P.N., An, L.T.H.: The subgradient extragradient method extended to equilibrium problems. Optimization 64(2), 225-248 (2012). https://doi.org/10.1080/02331934.2012.745528

11. Kim, J.-K., Anh, P.N., Hyun, H.-G.: A proximal point-type algorithm for pseudomonotone equilibrium problems. Bull. Korean Math. Soc. 49(4), 749-759 (2012). https://doi.org/10.4134/bkms.2012.49.4.749

12. Anh, P.N., Kim, J.K.: An interior proximal cutting hyperplane method for equilibrium problems. J. Inequal. Appl. 2012 Article ID 99 (2012). https://doi.org/10.1186/1029-242x-2012-99

13. Quoc, T.D., Anh, P.N., Muu, L.D.: Dual extragradient algorithms extended to equilibrium problems. J. Glob. Optim. 52(1), 139-159 (2011). https://doi.org/10.1007/s10898-011-9693-2

14. Anh, P.N., Kim, J.K.: Outer approximation algorithms for pseudomonotone equilibrium problems. Comput. Math. Appl. 61(9), 2588-2595 (2011). https://doi.org/10.1016/j.camwa.2011.02.052

15. Anh, P.N., Hai, T.N., Tuan, P.M.: On ergodic algorithms for equilibrium problems. J. Glob. Optim. 64(1), 179-195 (2015). https://doi.org/10.1007/s10898-015-0330-3

16. Kim, J.K., Anh, P.N., Hai, T.N.: The brucks ergodic iteration method for the Ky Fan inequality over the fixed point set. Int. J. Comput. Math. 94(12), 2466-2480 (2017). https://doi.org/10.1080/00207160.2017.1283414

17. Anh, P.N., Anh, T.T.H., Hien, N.D.: Modified basic projection methods for a class of equilibrium problems. Numer. Algorithms 79(1), 139-152 (2017). https://doi.org/10.1007/s11075-017-0431-9

18. Anh, P.N., Hien, N.D., Tuan, P.M.: Computational errors of the extragradient method for equilibrium problems. Bull. Malays. Math. Sci. Soc. 42(5), 2835-2858 (2018). https://doi.org/10.1007/s40840-018-0632-y

19. Combettes, P.L., Hirstoaga, S.A.: Equilibrium programming in Hilbert spaces. J. Nonlinear Convex Anal. 6(1), 117-136 (2005)

20. Tran, D.Q., Dung, M.L., Nguyen, V.H.: Extragradient algorithms extended to equilibrium problems. Optimization 57(6), 749-776 (2008). https://doi.org/10.1080/02331930601122876

21. Moudafi, A.: Proximal point algorithm extended to equilibrium problems. J. Nat. Geom. 15(1-2), 91-100 (1999)

22. Mastroeni, G.: On auxiliary principle for equilibrium problems. In: Equilibrium Problems and Variational Models. Nonconvex Optimization and Its Applications, vol. 68, pp. 289-298. Springer, Boston (2003)

23. Martinet, B.: Régularisation d'inéquations variationnelles par approximations successives. Rev. Fr. Inform. Rech. Oper. 4(R3), 154-158 (1970). https://doi.org/10.1051/m2an/197004r301541

24. Rockafellar, R.T.: Monotone operators and the proximal point algorithm. SIAM J. Control Optim. 14(5), 877-898 (1976) https://doi.org/10.1137/0314056

25. Cohen, G.: Auxiliary problem principle and decomposition of optimization problems. J. Optim. Theory Appl. 32(3) 277-305 (1980). https://doi.org/10.1007/bf00934554

26. Cohen, G.: Auxiliary problem principle extended to variational inequalities. J. Optim. Theory Appl. 59(2), 325-333 (1988). https://doi.org/10.1007/bf00938316

27. Korpelevich, G.: The extragradient method for finding saddle points and other problems. Matecon 12, 747-756 (1976)

28. Censor, Y., Gibali, A., Reich, S.: The subgradient extragradient method for solving variational inequalities in Hilbert space. J. Optim. Theory Appl. 148(2), 318-335 (2010). https://doi.org/10.1007/s10957-010-9757-3

29. Popov, L.D.: A modification of the Arrow-Hurwicz method for search of saddle points. Math. Notes Acad. Sci. USSR 28(5), 845-848 (1980). https://doi.org/10.1007/bf01141092

30. Tseng, P.: A modified forward-backward splitting method for maximal monotone mappings. SIAM J. Control Optim. 38(2), 431-446 (2000). https://doi.org/10.1137/s0363012998338806

31. He, B.: A class of projection and contraction methods for monotone variational inequalities. Appl. Math. Optim. 35(1), 69-76 (1997). https://doi.org/10.1007/bf02683320

32. Yamada, I.: The hybrid steepest descent method for the variational inequality problem over the intersection of fixed point sets of nonexpansive mappings. Stud. Comput. Math. 8, 473-504 (2001). https://doi.org/10.1016/s1570-579x(01)80028-8

33. Xu, H.K., Kim, T.H.: Convergence of hybrid steepest-descent methods for variational inequalities. J. Optim. Theory Appl. 119(1), 185-201 (2003). https://doi.org/10.1023/b:jota.0000005048.79379.b6

34. Bertsekas, D.P., Gafni, E.M.: Projection methods for variational inequalities with application to the traffic assignment problem. In: Mathematical Programming Studies, pp. 139-159. Springer, Berlin (1982). https://doi.org/10.1007/bfb0120965

35. Zhu, M., Chan, T.: An efficient primal-dual hybrid gradient algorithm for total variation image restoration. UCLA CAM report $34(2008)$

36. Flåm, S.D., Antipin, A.S.: Equilibrium programming using proximal-like algorithms. Math. Program. 78(1), 29-41 (1996). https://doi.org/10.1007/bf02614504

37. Van Hieu, D.: Halpern subgradient extragradient method extended to equilibrium problems. Rev. R. Acad. Cienc Exactas Fís. Nat., Ser. A Mat. 111, 823-840 (2017). https://doi.org/10.1007/s13398-016-0328-9 
38. Kassay, G., Hai, T.N., Vinh, N.T.: Coupling Popov's algorithm with subgradient extragradient method for solving equilibrium problems. J. Nonlinear Convex Anal. 19(6), 959-986 (2018)

39. Liu, Y., Kong, H.: The new extragradient method extended to equilibrium problems. Rev. R. Acad. Cienc. Exactas Fís. Nat., Ser. A Mat. (2018). https://doi.org/10.1007/s13398-018-0604-y

40. Polyak, B.T.: Some methods of speeding up the convergence of iteration methods. USSR Comput. Math. Math. Phys. 4, 1-17 (1964). https://doi.org/10.1016/0041-5553(64)90137-5

41. Beck, A., Teboulle M.: A fast iterative shrinkage-thresholding algorithm for linear inverse problems. SIAM J. Imaging Sci. 2, 183-202 (2009). https://doi.org/10.1137/080716542

42. Dong, Q.-L., Lu, Y.-Y., Yang, J.: The extragradient algorithm with inertial effects for solving the variational inequality. Optimization 65, 2217-2226 (2016). https://doi.org/10.1080/02331934.2016.1239266

43. Boţ, R.I., Csetnek, E.R., László, S.C.: An inertial forward-backward algorithm for the minimization of the sum of two nonconvex functions. EURO J. Comput. Optim. 4, 3-25 (2016). https://doi.org/10.1007/s13675-015-0045-8

44. Maingé, P.-E., Moudafi, A.: Convergence of new inertial proximal methods for DC programming. SIAM J. Optim. 19, 397-413 (2008). https://doi.org/10.1137/060655183

45. Moudafi, A.: Second-order differential proximal methods for equilibrium problems. J. Inequal. Pure Appl. Math. 4(1), $1-7(2003)$

46. Chbani, Z., Riahi, H.: Weak and strong convergence of an inertial proximal method for solving Ky Fan minimax inequalities. Optim. Lett. 7, 185-206 (2013). https://doi.org/10.1007/s11590-011-0407-y

47. Van Hieu, D., Quy, P.K., Van Vy, L.: Explicit iterative algorithms for solving equilibrium problems. Calcolo 56, Article ID 11 (2019). https://doi.org/10.1007/s10092-019-0308-5

48. Van Hieu, D.: An inertial-like proximal algorithm for equilibrium problems. Math. Methods Oper. Res. 88, 399-415 (2018). https://doi.org/10.1007/s00186-018-0640-6

49. Van Hieu, D.: New inertial algorithm for a class of equilibrium problems. Numer. Algorithms 80, 1413-1436 (2019). https://doi.org/10.1007/s11075-018-0532-0

50. Goebel, K., Reich, S.: Uniform Convexity, Hyperbolic Geometry, and Nonexpansive Mappings. Dekker, New York (1984)

51. Kreyszig, E.: Introductory Functional Analysis with Applications. Wiley, New York (1978)

52. Bianchi, M., Schaible, S.: Generalized monotone bifunctions and equilibrium problems. J. Optim. Theory Appl. 90, 31-43 (1996). https://doi.org/10.1007/bf02192244

53. Hieua, D.V.: Parallel extragradient-proximal methods for split equilibrium problems. Math. Model. Anal. 21,478-501 (2016). https://doi.org/10.3846/13926292.2016.1183527

54. van Tiel, J.: Convex Analysis: An Introductory Text, 1st edn. Wiley, New York (1984)

55. Bauschke, H.H., Combettes, P.L.: Convex Analysis and Monotone Operator Theory in Hilbert Spaces. Springer, New York (2011)

56. Alvarez, F., Attouch, H.: An inertial proximal method for maximal monotone operators via discretization of a nonlinear oscillator with damping. Set-Valued Var. Anal. 9, 3-11 (2001). https://doi.org/10.1023/a:1011253113155

57. Opial, Z.: Weak convergence of the sequence of successive approximations for nonexpansive mappings. Bull. Am. Math. Soc. 73, 591-598 (1967). https://doi.org/10.1090/S0002-9904-1967-11761-0

58. Konnov, I.: Combined Relaxation Methods for Variational Inequalities. Lecture Notes in Economics and Mathematical Systems, vol. 495. Springer, New York (2001)

59. Hu, X., Wang, J.: Solving pseudomonotone variational inequalities and pseudoconvex optimization problems using the projection neural network. IEEE Trans. Neural Netw. 17, 1487-1499 (2006). https://doi.org/10.1109/TNN.2006.879774

60. Shehu, Y., Dong, Q.-L., Jiang, D.: Single projection method for pseudo-monotone variational inequality in Hilbert spaces. Optimization 68, 385-409 (2019). https://doi.org/10.1080/02331934.2018.1522636

\section{Submit your manuscript to a SpringerOpen ${ }^{\circ}$ journal and benefit from:}

- Convenient online submission

- Rigorous peer review

- Open access: articles freely available online

- High visibility within the field

- Retaining the copyright to your article

Submit your next manuscript at $>$ springeropen.com 